Research Article

\title{
Numerical Investigation of Combustion Characteristics of a Wave Rotor Combustor Based on a Reduced Reaction Mechanism of Ethylene
}

\author{
Jianzhong Li $\mathbb{D}^{1}{ }^{1}$ Li Yuan, ${ }^{2}$ Wei Li, ${ }^{1}$ and Kaichen Zhang ${ }^{1}$ \\ ${ }^{1}$ Key Laboratory of Aero-engine Thermal Environment and Structure, Ministry of Industry and Information Technology, \\ Nanjing University of Aeronautics and Astronautics, 29 Yudao St., Nanjing 210016, China \\ ${ }^{2}$ School of National Defense Engineering, The Army Engineering University of PLA, 88 Biaoying Rd., Nanjing 210007, China
}

Correspondence should be addressed to Jianzhong Li; ljzh0629@nuaa.edu.cn

Received 14 May 2018; Accepted 29 August 2018; Published 1 November 2018

Academic Editor: Dan Zhao

Copyright (C) 2018 Jianzhong Li et al. This is an open access article distributed under the Creative Commons Attribution License, which permits unrestricted use, distribution, and reproduction in any medium, provided the original work is properly cited.

\begin{abstract}
To improve simulations of the flame and pressure wave propagation process and investigate the combustion characteristics of a wave rotor combustor (WRC), direct relation graphs with error propagation (DRGEP), quasi-steady-state assumption (QSSA), and sensitivity analysis were used to establish a reduced reaction mechanism comprised of 23 species and 55 elementary reactions, based on the LLNL N-Butane mechanism. The reduced reaction mechanism of ethylene was combined with an eddy dissipation concept (EDC) model to simulate the flame propagation characteristics in a simplified WRC channel. The effects of spoilers with different blockage ratios and hot-jets of different species on combustion characteristics of flame propagation and pressure rise in the WRC channel were investigated. When the heated inert air was used as hot-jet, the ignition delay time of WRC would increase, which indicated that the activity of the burned gas from the hot-jet igniter would affect the ignition delay time. The spoiler facilitates the coupling of flame and shock waves to reduce the coupling time and distance. With the blockage ratio of the spoiler increasing, the coupling time and distance would be reduced.
\end{abstract}

\section{Introduction}

An aeroengine is comprised of three main components, such as compressor, combustor, and turbine. The chemical energy in the fuel is transformed into thermal energy in the combustion chamber. The thermal energy is used to heat highpressure air after boosting the pressure in the compressor to the allowable turbine inlet temperature. The heat capacity of the working medium can be improved by enhancing enthalpy, which directly affects the overall performance of an aeroengine [1-3]. To further enhance the aeroengine and achieve more favorable performance, improvements to the combustor can be made with respect to two aspects. One is increasing the turbine inlet temperature (i.e., the traditional method for enhancing performance), the other is exploring novel technologies (i.e., replacing conventional isobaric combustion modes with constant-volume combustion modes of higher cycle efficiency) [4-6]. Compared to results based on a traditional isobaric combustion mode, the thermal efficiency in the thermodynamic cycle of a gas turbine engine with a wave rotor combustor (WRC) using constant-volume combustion can be enhanced by $30 \% \sim 50 \%$, thereby realizing a huge leap forward in terms of power performance.

A WRC is mainly comprised of an inlet duct, wave rotor channel, outlet duct, and ignitor and adopts a high-efficiency constant-volume combustion mode. As shown in Figure 1, the wave rotor channel forms a direct passage structure around the axis to form a rotary barrel, which is in sliding contact with the inlet and outlet ducts via a slide sealing technique. Corresponding ports are set on both the inlet and outlet ducts and bearings fix the wave rotor onto the axis. When the WRC operates, rotation of the axis is driven by the motor, which further drives the wave rotor channel to rotate at high speed. Moreover, both the inlet and outlet ducts remain stationary. Accordingly, flow in both inlet and outlet ducts is periodically exposed to the channel, which could produce 


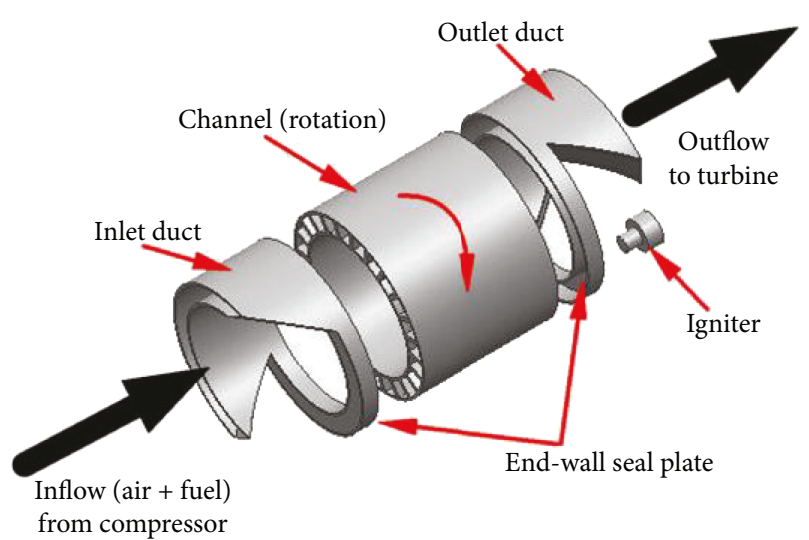

FIgURE 1: The typical WRC model.

complex waves and facilitate energy exchange. While the channel is filled with fuel/air mixture, the hot-jets enter the channel of WRC and the combustible fuel/air mixture is ignited to realize the high-efficiency constant-volume combustion. Afterwards, the outlet duct is opened to finish the exhaust of burned gas.

As shown in Figure 2, the entire WRC operating process can be divided into six procedures. First, the inlet duct of the wave rotor channel opens and the outlet duct closes. At this stage, the end of the channel is mostly filled with combustible mixture, and the front region is partly filled with air. In the second step, both the inlet and outlet ducts close, the hotjet enters the wave rotor channel, and the combustible fuel/air mixture is ignited; i.e., the constant-volume combustion process begins. In the third step, after the combustion is completed, the channel is filled with high-temperature and high-pressure burned gas, and the outlet duct opens to discharge the burned gas from the wave rotor channel. This is accompanied by the production of an expansion wave, which propagates upstream in the channel. In the fourth step, the inlet duct opens to fill the chamber with combustible fuel/air mixture so that the high-temperature burned gas produced in the previous cycle could be isolated from the air flow. In the fifth step, both the inlet and outlet ducts open and the inlet duct is filled with the premixed combustible fuel/air mixture. Finally, the outlet duct closes, the inlet duct remains open, and shock waves are produced at the outlet duct. This process is also referred to the precompression process of the WRC $[7,8]$.

Currently, a large emphasis is placed on research of WRC in which micromolecule gaseous hydrocarbon fuels such as methane, ethylene, and propane are used. However, directly using macromolecule liquid kerosene under a special operating environment in a WRC is difficult and a series of measures should be taken, such as dissociation and gasification [9]. Ethylene is a type of micromolecule hydrocarbon fuel that possesses much higher ignition, combustion velocity, and explosibility than other micromolecule hydrocarbon fuels making it suitable for use in WRCs [10]. Combustion of ethylene in the wave rotor channel is nonpremixed turbulent combustion, and previous numerical simulations on combustion in WRC generally adopt a single-step reaction mechanism [7]. The single-step reaction mechanism of ethylene can be used to provide flow distribution and temperature distribution information in the WRC channel; however, it fails to effectively analyze detailed ignition processes and flame front propagation. Therefore, it is necessary to establish a reduced mechanism for simulating the combustion process of ethylene in a WRC.

Detailed chemical reaction mechanisms of ethylene are generally quite complex. Wide variation of certain parameters including temperature, pressure, equivalence ratio, mixing time, and dwelling time should be taken into account. Therefore, detailed reaction mechanisms generally include hundreds or even thousands of elementary reactions. The combustion of hydrogen is the simplest hydrocarbon combustion. Nonetheless, the detailed chemical reaction mechanism includes hundreds of steps. The relevant mechanisms under low temperatures are particularly complex. At present, a number of common detailed chemical reaction mechanisms are used, such as 111 species and 784 elementary reactions proposed by Wang et al. [11], another reaction mechanism including 127 species and 1207 elementary reactions proposed by Konnov [13], and the LLNL N-Butane mechanism. Unfortunately, these detailed mechanisms are too complex to be directly applied in practical situations.

In recent years, reduced mechanisms of ethylene have been investigated. Liu et al. applied reaction path analysis and the approximate trajectory optimization algorithm (ATOA) to simplify the oxidation mechanism of ethylene and constructed a reduced mechanism including 32 species and 194 elementary reactions [14]. By analyzing reaction paths, Yu et al. constructed a reduced mechanism of ethylene with 56 species [15]. Based on the detailed reaction mechanisms of ethylene chemical reactions, Zhang et al. performed systematic simulations on the production of black smoke and precursors of the intermediates during the oxidation process of ethylene [16]. Previous investigations of reduced mechanisms of ethylene mainly focus on the oxidation mechanism, but do not effectively capture the development of waves and flames in WRCs. In addition, some reduced mechanisms do not satisfy the requirements of CFD software.

At present, methods commonly used for simplifying detailed chemical reaction models include sensitivity analysis, principal component analysis (PRA), computational singular perturbation (CSP), direct relation diagram (DRG), reaction path analysis, and quasi-stationary approximation analysis (QSSA) [17]. More specifically, during the simplification process, a skeletal mechanism is first constructed, then stiffness problems in the system are eliminated to acquire a reduced mechanism with fewer species and fewer elementary reactions.

In this study, a DRG was first used to construct a model of ethylene combustion, then stiffness problems were addressed by means of QSSA and sensitivity analysis, and finally, a reduced mechanism of ethylene including 23 species and 55 elementary reactions was established. Using the detailed and reduced mechanisms, combustion processes of ethylene in the shock tube were calculated, and calculated ignition delay time data as well as overall variation of reactants and products were compared to validate the effectiveness of the 


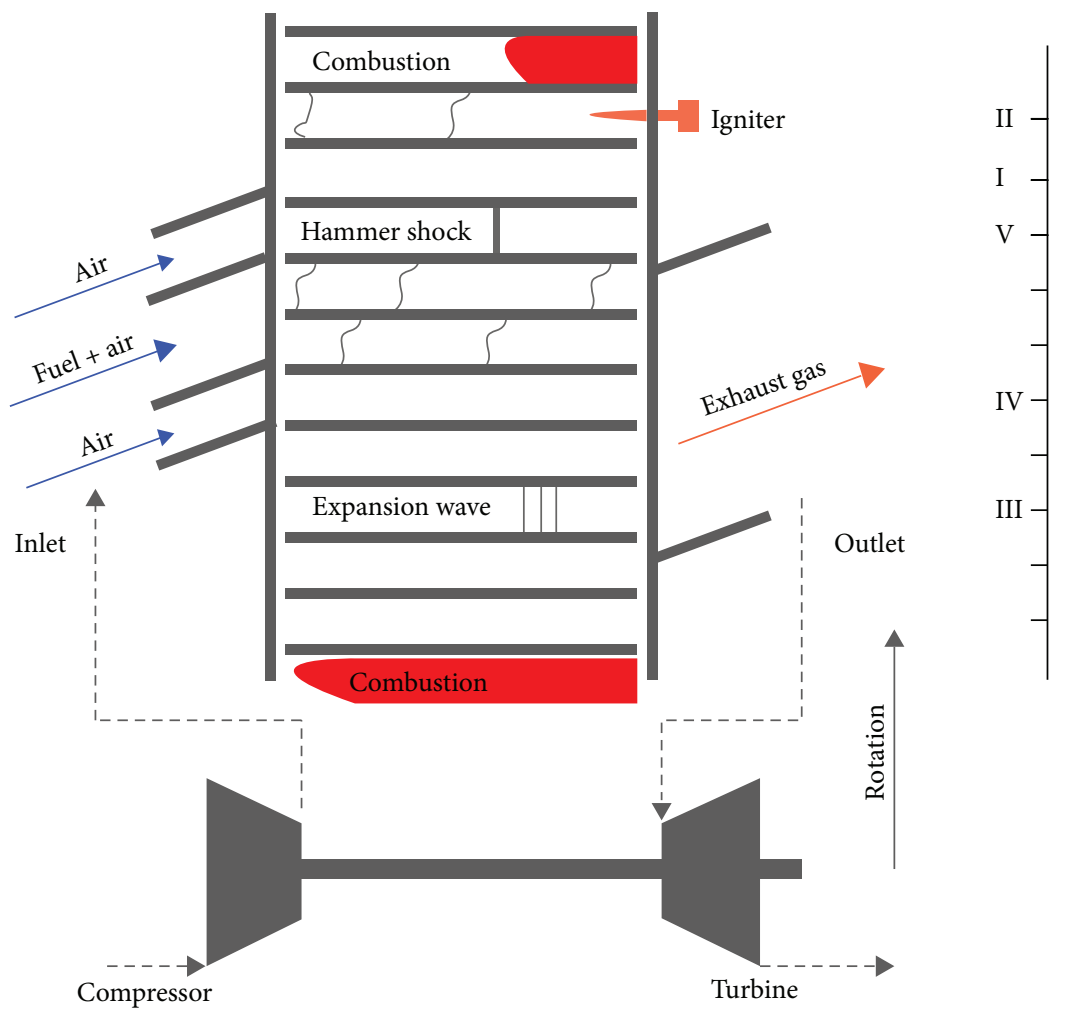

FIGURE 2: Illustration of the operating process for WRC.

reduced mechanism. Furthermore, a simplified physical model of the WRC was established. Combining the reduced mechanism and EDC combustion model, the combustion process in the wave rotor channel was simulated to determine the effects of the activity of the burned gas from the hot-jet igniter and spoilers with various blockage ratios on the propagation characteristics of shock wave and flames in the wave rotor channel.

\section{Simplification and Validation of Ethylene Reaction Mechanisms}

Detailed chemical reaction mechanisms are generally complex. Wide variation in temperature, pressure, and equivalence ratio, as well as mixing and dwelling times, should be considered when establishing new mechanisms. Therefore, hundreds or even thousands of elementary reactions must be included. Common mechanisms, species, numbers of elementary reactions, and application ranges are listed in Table 1.

Each detailed chemical reaction mechanism has its own application conditions. The production and emission of NOx were taken into account in the Konnov mechanism but neglected in the mechanism proposed by H. Wang. Simulation precision for combustion processes decreases when the established model is outside the application range. In some cases, established mechanisms may not be applicable at all. During simulations of medium- and high-temperature operating processes of a WRC, production of NOx should be neglected.
TABle 1: Summary of common detailed chemical reaction mechanisms of ethylene.

\begin{tabular}{lccc}
\hline $\begin{array}{l}\text { Name of } \\
\text { mechanisms }\end{array}$ & $\begin{array}{c}\text { Number of } \\
\text { species }\end{array}$ & $\begin{array}{c}\text { Number of } \\
\text { elementary } \\
\text { reactions }\end{array}$ & References \\
\hline GRI-Mech 3.0 & 53 & 325 & {$[17]$} \\
UC San Diego & 46 & 235 & {$[18]$} \\
Konnov & 127 & 1207 & {$[13]$} \\
H. Wang & 75 & 529 & {$[11]$} \\
LLNL N-Butane & 155 & 689 & {$[12]$} \\
\hline
\end{tabular}

Two important parameters are generally used for evaluating chemical reaction mechanisms, ignition delay time and flame propagation velocity. In combustion, ignition delay is a ubiquitous phenomenon and refers to the fuel/air mixture not immediately igniting and burning when the mixture temperature is higher than the ignition temperature. In general, ignition delay time has several definitions, and among these, the most common are $\mathrm{OH}$ maximum moment and $\mathrm{CH}$ maximum moment. In this study, $\mathrm{CH}$ maximum moment was selected for measuring the ignition delay time. Flame is always measured by the propagation speed of flames in laminar premixed combustion. Numerous studies have been performed on the ignition of ethylene. The ignition delay time of ethylene and propagation speed of laminar premixed flames have been acquired. Related ignition delay times of ethylene in the shock tubes and propagation velocities of flames in premixed flame furnaces are listed in Table 2. 
TABLE 2: Experimental data of ignition delay time and flame propagation speed under certain conditions.

\begin{tabular}{lccccc}
\hline Equivalence ratio & Percentage of diluent gas (\%) & Pressure (atm) & Temperature (K) & Definition/method & References \\
\hline $1,1.5,3$ & $98,97,96$ & $1-5$ & $1400-2100$ & $\mathrm{CH}^{*}$ onset/sidewall & [19] \\
1 & 96.75 & $1-3$ & $1000-1800$ & $\mathrm{CH}^{*}$ onset/endwall & [20] \\
$0.5-1.4$ & 21 & 1 & 298 & Counter-flow/nonlinear extrapolation & [21] \\
$0.5-1.4$ & 21 & $1,2,5$ & 298 & $\begin{array}{c}\text { Outwardly propagating spherical } \\
\text { flame/nonlinear extrapolation }\end{array}$ & [22] \\
\hline
\end{tabular}

In this study, some common detailed chemical reaction models of ethylene were selected and used to create a closingphase homogenous model and laminar premixed flame model in Chemkin-Pro combustion simulation software. The partially stirred reactor (PaSR) model was used for calculating the ignition delay time. Moreover, both the ignition process of ethylene in a shock tube and the laminar combustion process in a premixed furnace were simulated. Conditions used in calculations were identical to experimental conditions. A comparison of the results is presented in Figure 3.

From Figure 3(a), it can be observed that the UC San Diego, GRI-3.0, H. Wang, and LLNL, N-Butane mechanisms all predict the ignition delay time of ethylene relatively closely and are consistent with experimental data. Overall, the predicted ignition delay time using the GRI-3.0 mechanism is lower than values predicted using other detailed chemical mechanisms; however, using LLNL N-Butane, the predicted value is slightly higher. Two sets of experimental data agree well with each other in the high-temperature region but exhibit a certain amount of deviation in the low-temperature region. The reason for this is that two different methods were used for measuring the ignition delay time. More specifically, Kalitan et al. used ignition traces on the side wall as the measuring point of ignition delay time, whereas Baker and Skinner conducted measurements using ignition traces on the end wall. The results of Kalitan et al. showed that ignition traces on the side wall output have a quicker ignition delay time than those on the end wall, particularly in the lowtemperature reaction zone which is highly sensitive to temperature. As shown in Figure 3(b), the additional three detailed chemical reaction mechanisms, except GRI-3.0, can reasonably predict the laminar premixed flame propagation speed of ethylene. According to the ignition delay time and flame speed in Figure 3, the UC San Diego mechanism, LLNL $\mathrm{N}$-Butane mechanism, and $\mathrm{H}$. Wang mechanism were selected as the comprehensive detailed kinetic mechanisms and three reduced reaction mechanisms were gained. The three reduced reaction mechanisms were applied in the numerical simulation for the WRC, but the reduced reaction mechanisms from UC San Diego mechanism and H. Wang mechanism would make a floating point error and cause the calculation to stop. The reduced reaction mechanism from the LLNL N-Butane mechanism could be applied in the numerical simulation for WRC. Output of the LLNL NButane mechanism results in slightly smaller predicted values. Then, the optimizing and perfecting of the reduced reaction mechanism from the LLNL N-Butane mechanism were focused on and the other reduced reaction mechanisms were given up. Considering construction conditions, the
LLNL N-Butane mechanism was selected as the detailed chemical reaction mechanism of ethylene in this study.

The LLNL N-Butane model included 155 species and 689 elementary reactions in total. Although the LLNL N-Butane mechanism can adequately describe the combustion characteristics of ethylene, it cannot be directly applied in combustion simulations. Fluid simulation software always presents certain limitations in coupled elementary reaction models. Further, large differences in the concentration and time scale of various chemical species involved in the chemical reaction as well as stiffness problems in calculations lead to numerous issues in applying simple combustion simulations. Performing simulations on unsteady and turbulent WRC combustions are particularly difficult. Therefore, before coupling the elementary reaction model for the combustion simulation, the detailed chemical reaction model should be reduced to one that used fewer species and elementary reactions, to accurately replace the detailed chemical reaction model.

The skeletal mechanism of ethylene was first constructed using DRG. Stiffness problems in the skeletal mechanism were eliminated by using QSSA and sensitivity analysis results to establish the reduced chemical reaction model. Correlation coefficients were first determined among the various chemical species and the importance of each component was assessed. Figure 4 displays a typical DRG that reflects the relationships among species.

If removing component $\mathrm{B}$ can lead to the production and consumption of component $\mathrm{A}$, as well as great error, the line diagram from $A$ to $B$, the skeletal mechanism in the left part of Figure 4, should include components A, B, and D. Further, components $\mathrm{E}$ and $\mathrm{F}$ are coupled but irrelevant to components A, B, and D. Therefore, components E and F should both be either removed or retained. Setting appropriate thresholds in the skeletal mechanism using DRG is particularly important for establishing an accurate reduced mechanism.

The QSSA method judges whether species are in quasisteady state based on the quasi-steady-state hypothesis. The mechanism is simplified by removing quasi-steady materials in the chemical reactions. According to the quasi-steadystate hypothesis, the production rate of material in the reaction is approximately equal to the consumption rate, and the following expression can be derived:

$$
\frac{\mathrm{d} y k}{\mathrm{~d} t}=\sum_{i=1}^{l} v i, k \quad w i=0,
$$

where $y k$ denotes the concentration of the $k-$ th component, $t$ denotes time, $l$ denotes the total number of reactions, $v i, k$ 


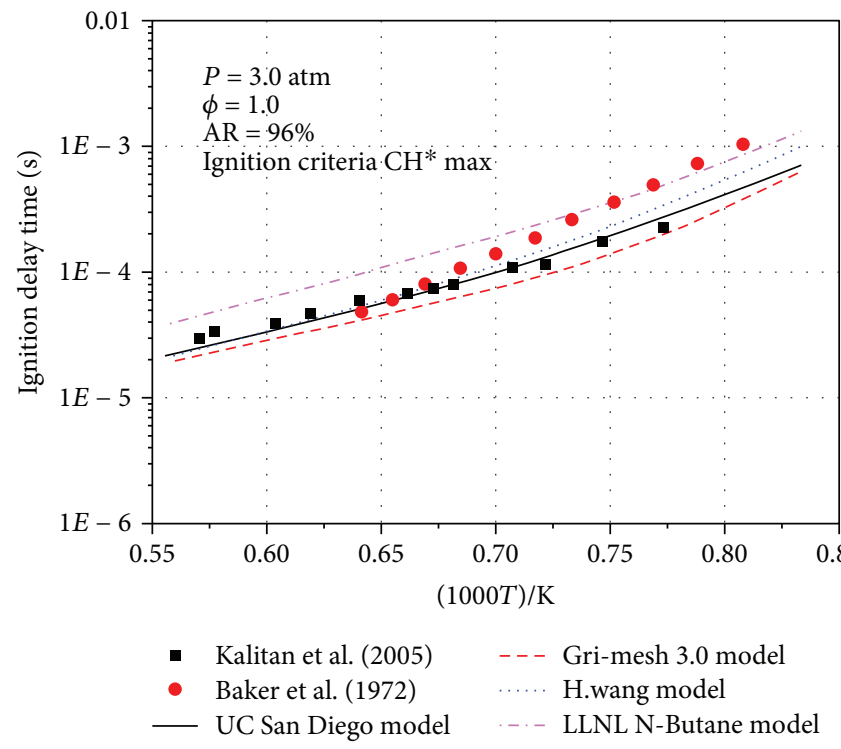

(a)

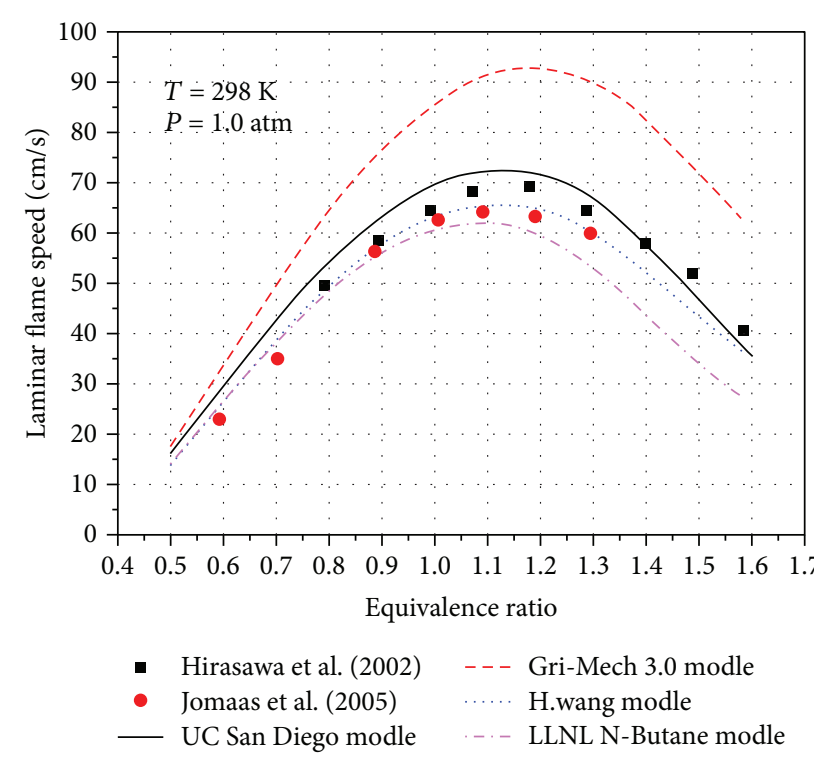

(b)

FIGURE 3: Comparison of calculated values versus experimental results, in which (a) ignition delay time and (b) flame propagation speed.

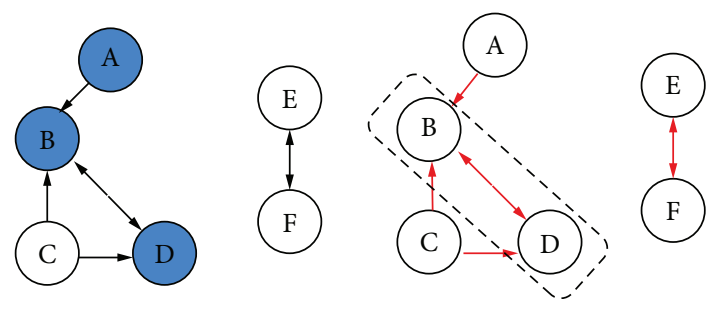

Figure 4: Typical DRG among various species.

represents the coefficient of the $k$ - th component of the $i-$ th reaction, and $w i$ is the net production rate of the $i-$ th reaction. The quasi-steady-state species can be added to the unsteady-state species via the change of matrix to remove quasi-steady species and acquire the reduced mechanism in the total reaction format.

Using sensitivity analysis, the degree of sensitivity of calculation results to the reaction parameters was calculated by changing the parameters in the chemical reaction system. Through sensitivity analysis, important steps in the elementary reactions can be assessed. Reactions with less sensitivity were eliminated to simplify the mechanisms and address stiffness problems in the chemical reaction system.

With respect to the detailed LLNL N-Butane mechanism, the laminar premixed flame model was calculated under a pressure of 1 atm, unburned temperature of $298 \mathrm{~K}$, equivalence ratio of $0.6 \sim 1.2$, and mass flow at the inlet equal to $0.02 \mathrm{~g} /\left(\mathrm{cm}^{2} / \mathrm{sec}\right)$. Flame speed was used as the target error for control, defined as

$$
\text { Error tolerance }=\frac{|V a-V s|}{(R \times|V a|+A)},
$$

where $R$ denotes the relative error and $A$ is the absolute error.
The relationship between number of species and error is shown in Figure 5. Using the mechanism with a great number of species results in less error, and greater errors are produced as more species are removed. As the number of species in the mechanism decreases, great errors are produced when fewer species are removed. With a small number of species in the mechanism, species are tightly coupled and error does not always increase and is even significantly reduced after removing certain species.

To acquire an accurate skeletal mechanism with fewer species, a skeletal mechanism including 33 species and 180 elementary reactions was first selected. Then, QSSA was carried out on the skeletal mechanism. Results demonstrated that ten chemical compounds, $\mathrm{C}_{3} \mathrm{H}_{6}, \mathrm{C}_{3} \mathrm{H}_{5}, \mathrm{HCOH}, \mathrm{C}_{2} \mathrm{H}_{6}$, $\mathrm{CH}_{2} \mathrm{OH}, \mathrm{C}_{4} \mathrm{H}_{10}, \mathrm{C}_{2} \mathrm{H}, \mathrm{CH}_{3} \mathrm{O}, \mathrm{CH}_{2}(\mathrm{~s})$, and $\mathrm{CH}_{2} \mathrm{CHCHO}$, were approximately in steady state and thus removed. Using this method, a skeletal model comprised of 23 species and 116 elementary reactions was acquired. Finally, based on sensitivity analysis results, a reduced mechanism model of 23 species and 55 elementary reactions was established.

\section{Validation of Reduced Chemical Reaction Mechanism for Ethylene Combustion}

Simplification of the model aims to adequately use fewer species and elementary reactions to replace the detailed mechanisms. However, there seems to be a contradictory relationship. The reduced mechanism can be considered reasonable within a certain error range.

Simulation results for ignition delay time and flame propagation speed using reduced mechanism, skeletal mechanism, and detailed mechanism are shown in Figure 6. According to the ignition delay time curves based on different calculation conditions, the present reduced mechanism provides accurate predictions within the largest range of 


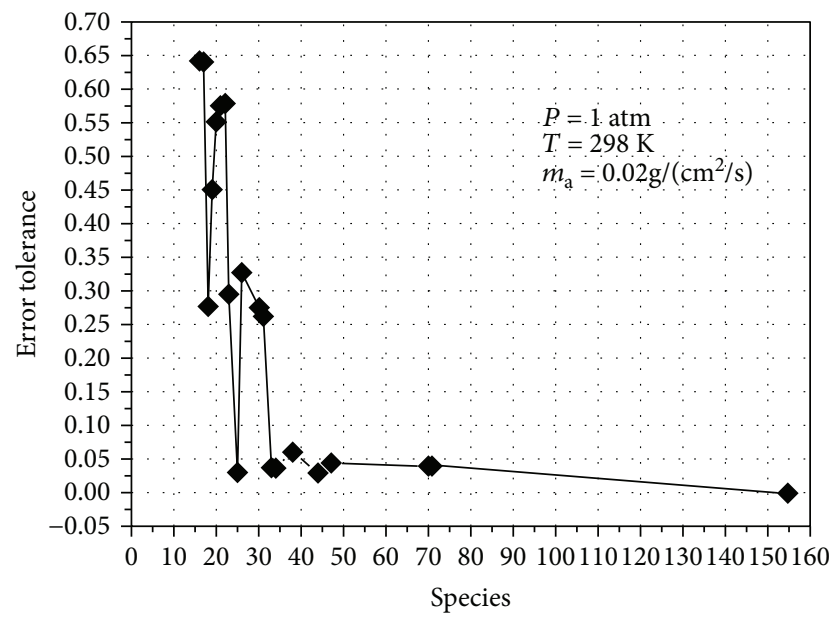

FIGURE 5: Relationship between number of species and calculated error.

thermodynamic parameters. Moreover, the skeletal mechanism achieved fairly accurate predictions. Overall, ignition delay time decreases with increasing initial temperature. Ignition is difficult at low temperatures and ignition delay time increases as the gradient of the initial temperature variation curve increases. This is due to the fact that a lot of chain reactions are removed in the reduced mechanism and ignition is more difficult than for the detailed mechanism. Accordingly, the curve obtained using the reduced mechanism has a more obvious change in gradient than the detailed mechanism at low temperatures, thereby leading to larger differences in the ignition delay time. The variation of ignition delay time with pressure of the reduced mechanism is consistent with results using the detailed mechanism. Using the reduced mechanism, variation of ignition delay time with equivalence ratio is almost consistent with the more detailed mechanism. The ignition delay time error may be as great as $22 \%$. The reduced mechanism also provides an accurate prediction of propagation speed of laminar premixed flames, and the predicted flame propagation prediction speed at the stoichiometric ratio are even more accurate than with the detailed mechanism. The flame speed error may be as great as $8 \%$. To obtain more in-depth knowledge of flame structure and concentration changes of various species in the chemical reaction zone, flame structure was also analyzed using the combustion furnace model, as shown in Figure 7. The curves representing the concentration of various chemicals and byproducts over time generated using the three mechanisms are similar, except that the concentration of $\mathrm{HO}_{2}$ in certain regions with low flame heights differs. This can be attributed to deleting certain important reactions related to the consumption of $\mathrm{HO}_{2}$. Overall, the reduced mechanism generates accurate predictions of chemical component concentrations at different flame heights. The $\mathrm{OH}$ concentration error may be as great as $7 \%$. Using the reduced mechanism, the predicted results for temperature on the flame front are lower than values predicted using the detailed mechanism by approximately $100 \mathrm{~K}$. The temperature error may be as great as $6 \%$. Predicted results of temperature distribution using the two mechanisms correspond well with each other for engineering applications. The errors of the results in Figures 6 and 7 are similar to the results of reference [23], and the variation tendency matches the data of the detailed mechanism.

Based on a comprehensive comparison, it can be concluded that the reduced mechanism with 23 species can accurately describe the ignition delay time, flame propagation speed, and flame structure and produces values relevant to certain engineering applications, shown in Table 3.

To further identify differences between the reduced mechanism and detailed mechanism and to visually display the oxidation paths involved in the reaction, reaction paths at an initial temperature of $1350 \mathrm{~K}$ were analyzed, as shown in Figure 8. The thickness of the line indicates the importance of elementary chemical reactions. It can be observed that oxidation occurs along the path $\mathrm{C}_{2} \mathrm{H}_{4}-\mathrm{C}_{2} \mathrm{H}_{3}-\mathrm{C}_{2} \mathrm{H}_{2}$ - $\mathrm{HCCO}$ $\mathrm{HCO}-\mathrm{CO}$ in the reduced mechanism. In contrast, oxidation in the detailed mechanism occurs along many paths, including some initial chain reactions such as $\mathrm{C}_{2} \mathrm{H}_{5}-\mathrm{C}_{2} \mathrm{H}_{4}$. Based on the initial chain reactions, the detailed mechanism results in more accurate prediction of ignition delay time in the lowtemperature region.

For sensitivity analysis, calculation conditions were identical to those used in the reaction path analysis. The important parameters of each reaction can be assessed using results of the sensitivity analysis. A comparison of the sensitivities of several important chemical species is presented in Figure 9 and identifies important reactions used in the reduced mechanism.

\section{Computational Approach and Modeling}

4.1. Mathematical Descriptions and Numerical Models. Navier-Stokes equations [24-26] were used in the numerical simulation and have been extensively applied to $2 \mathrm{D}$ nonsteady flows for simulating dynamic processes of fluids. The equations were solved by Fluent CFD software. Since flow and combustion in the WRC exhibit distinct unsteady characteristics, Pressure-Implicit with the Splitting of Operators (PISO) algorithm was selected for iteration of the flow field. Similar to the SIMPLE algorithm and SIMPLEC algorithm, a modified step was added to the PISO algorithm to satisfy the momentum equation and continuity equation simultaneously. Accordingly, PISO can accelerate the convergence of a single iterative step and is therefore more applicable to transient problems [27]. Near-wall regions were described by standard wall functions, and the shear stress transport (SST) $k-\omega$ turbulence model was used. In general, $k-\varepsilon$ models are suitable for cases where the boundary layer maintains a stable pressure. Although the SST $k-\omega$ doubleequation turbulence model obeys assumptions of isotropic turbulence similar to the standard $k-\varepsilon$ model, renormalization group (RNG) $k-\varepsilon$ model, and realizable $k-\varepsilon$ model, after appropriate modifications, the SST $k-\omega$ model can be used for calculating viscous internal layers in near-wall regions. Thus, the SST $k-\omega$ model is preferable for simulating flow fields with varying pressure gradients.

The combustion process in a WRC involves turbulent flow and chemical reaction. The reduced mechanism of 


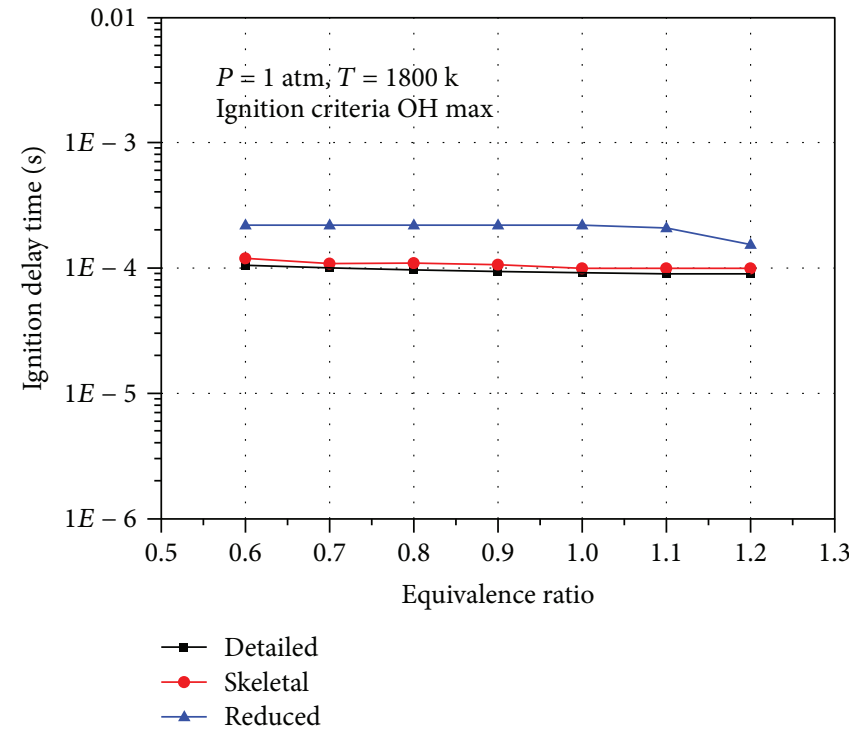

(a)

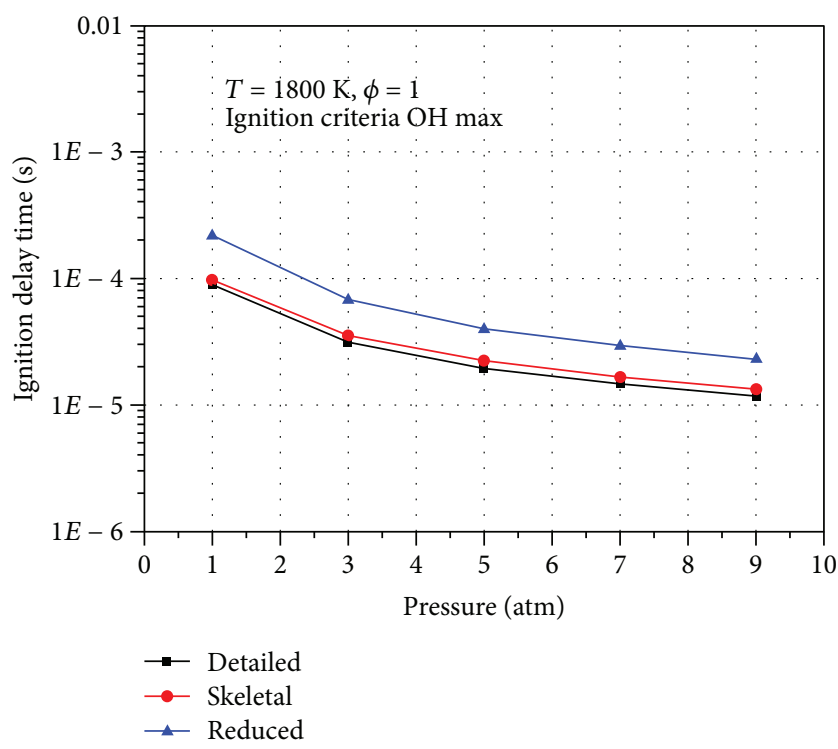

(c)

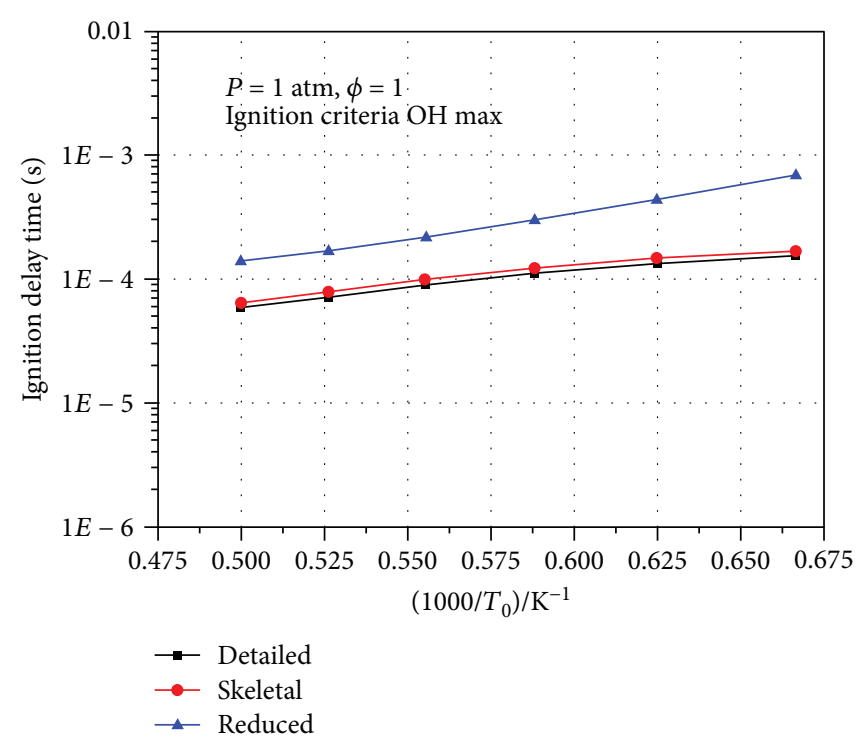

(b)

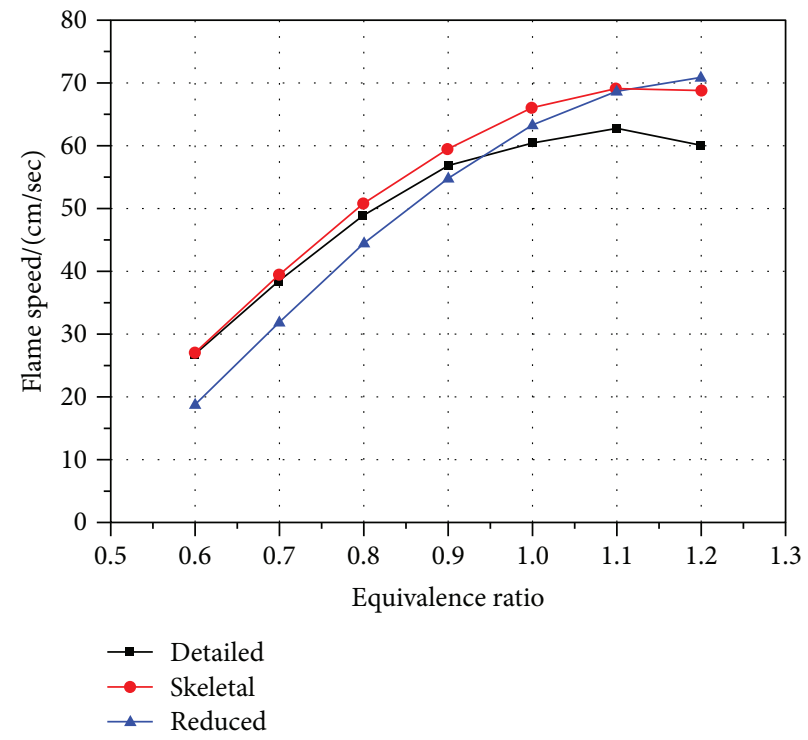

(d)

FIGURE 6: Simulation results for ignition delay time and flame propagation speed using reduced mechanism, skeletal mechanism, and detailed mechanism.

ethylene included 23 species and 55 elementary reactions. In turbulent combustion, the turbulent flow and chemical reaction are highly correlated and have mutual effects. Specifically, turbulent flow affects the time-average chemical reaction rate by increasing mixing while the heat released during the chemical reaction affects turbulent flow. A reasonable and economic turbulent combustion model is the key to our numerical simulation. The eddy dissipation concept (EDC) model was selected, which is an extended application of the eddy dissipation (ED) model in terms of fine chemical reaction mechanisms, including turbulent flow, and includes detailed chemical reaction mechanisms. With EDC, chemical reactions are assumed to occur in a small turbulent structure at the microscale, and chemical reactions at the microscale occur after a particular time scale. The reduced reaction mechanism of ethylene was combined with an eddy dissipation concept (EDC) model to simulate the flame propagation characteristics in a simplified WRC channel. The secondorder upwind discrete scheme and PISO algorithm were also used and exhibit remarkable advantages for solving transient problems. To improve calculation precision, the time step was set as $3 \times 10^{-7} \mathrm{~s}$.

\subsection{Computational Configuration and Boundary Conditions.} Establishing a numerical simulation model is a comprehensive process in which numerous factors, including the particular research objectives and simulation precision, should be considered. The WRC was investigated in this study, as shown in Figure 10, with the aim of determining the propagation characteristics of waves and flames in the WRC. The 


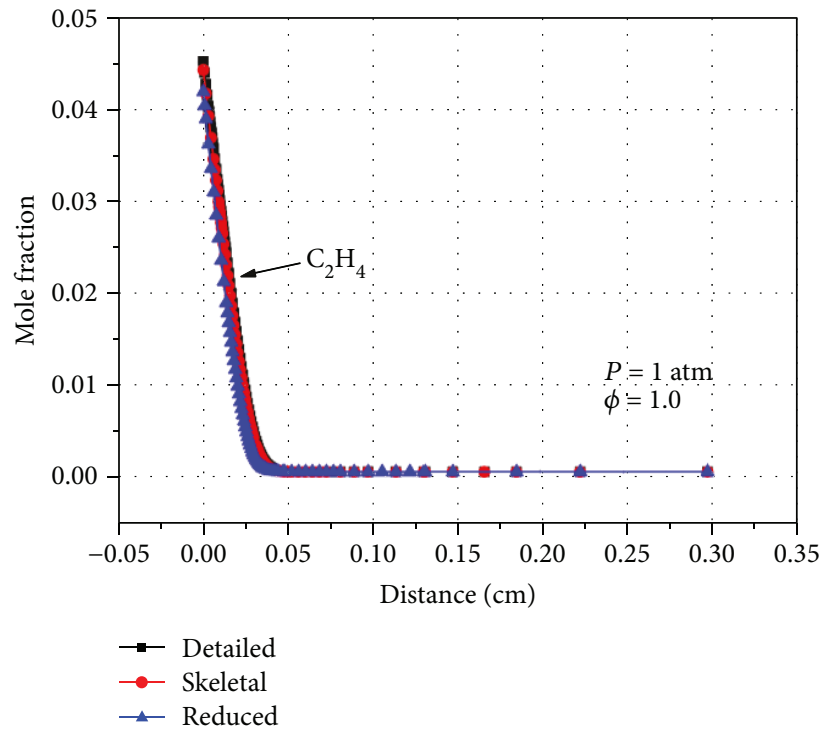

(a)

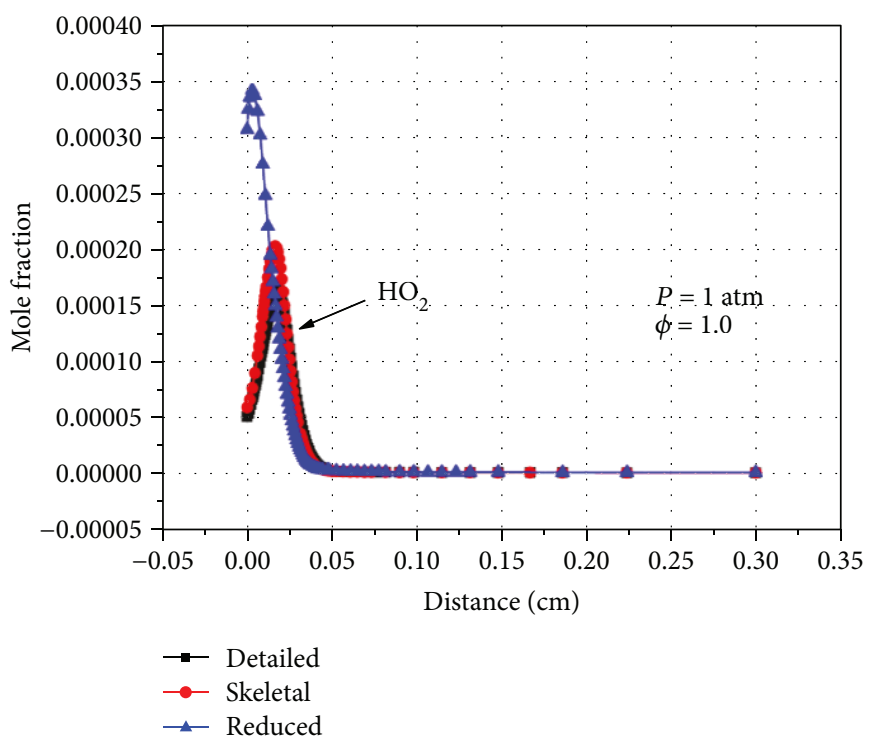

(c)

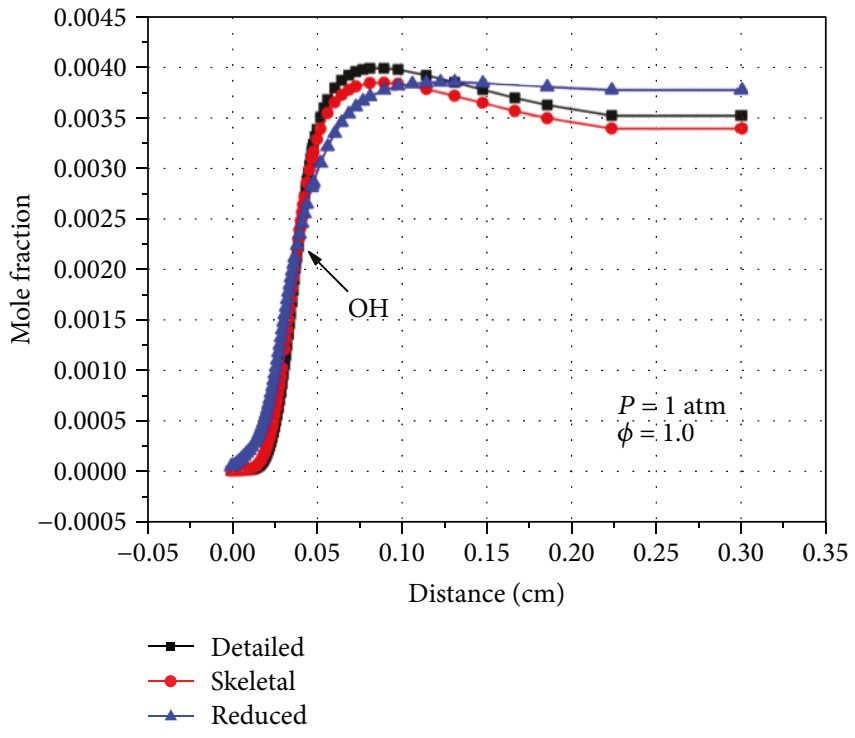

(b)

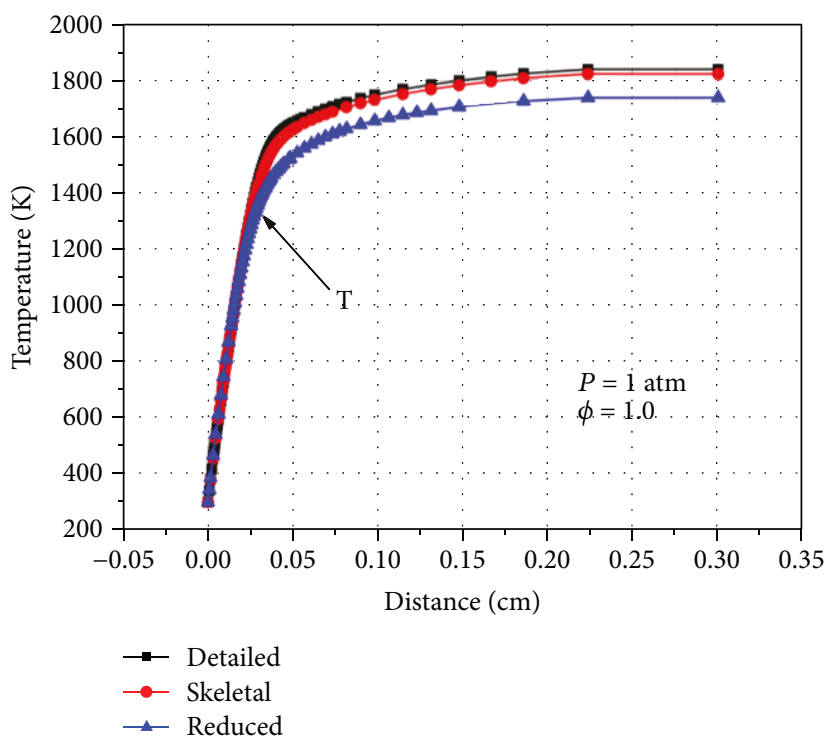

(d)

FIGURE 7: Changes in concentration of various chemical reagents and by-products calculated based on reduced mechanism, skeletal mechanism, and detailed mechanism.

ignition and combustion processes should first be extracted and a simulation model of the single-channel WRC constructed. A number of factors such as interactions among different channels and filling of the chamber with combustible fuel/air mixture were neglected in this model. Therefore, 2D simulation models of the WRC were established to simulate its complete operating process.

With regard to a WRC, the operating process is quite complex involving a number of processes including filling the chamber with combustible fuel/air mixture, ignition, flame formation and propagation, wave formation and propagation, and exhaust of burned gas. A simulation of the ignition process in the WRC was first conducted. In general, the ignition process includes some unusual phenomena such as the triggering and propagation of detonation waves.
Denotation waves always have a small characteristic scale, $4 \sim 6$ orders of magnitude lower than in experimental systems and 10 orders of magnitude lower than practical results. Thus, certain requirements for the numerical simulation process can be defined: (1) small mesh size, (2) relatively small time step, (3) huge computation requirements due to the detailed chemical reaction mechanism, and (4) unsteady simulation. Even simple 2D simulations can last several days. Considering practical conditions, the channel length in the WRC was set to approximately $200 \mathrm{~mm}$, which is a relatively short distance, and therefore makes it difficult to experimentally determine the detonation combustion conditions from deflagration to detonation. Based on unknown detonation combustion conditions in the WRC, it is difficult to directly carry out numerical simulations of the WRC operating 
TABLE 3: Elementary reactions in reduced mechanism.

\begin{tabular}{|c|c|c|c|c|c|}
\hline No. & Reaction steps & No. & Reaction steps & No. & Reaction steps \\
\hline 1 & $\mathrm{oh}+\mathrm{h} 2=\mathrm{h}+\mathrm{h} 2 \mathrm{o}$ & 20 & $\operatorname{ch} 3+o=\operatorname{ch} 2 o+h$ & 39 & $\mathrm{c} 2 \mathrm{~h} 3+\mathrm{h}=\mathrm{c} 2 \mathrm{~h} 2+\mathrm{h} 2$ \\
\hline 2 & $\mathrm{o}+\mathrm{oh}=\mathrm{o} 2+\mathrm{h}$ & 21 & $\operatorname{ch} 3+\mathrm{oh}=\mathrm{ch} 2 \mathrm{o}+\mathrm{h} 2$ & 40 & $\mathrm{c} 2 \mathrm{~h} 3+\mathrm{o} 2=\mathrm{ch} 2 \mathrm{o}+\mathrm{hco}$ \\
\hline 3 & $\mathrm{o}+\mathrm{h} 2=\mathrm{oh}+\mathrm{h}$ & 22 & $\operatorname{ch} 3+\mathrm{h}=\operatorname{ch} 2+\mathrm{h} 2$ & 41 & $\mathrm{c} 2 \mathrm{~h} 3+\mathrm{o} 2=\mathrm{ch} 2 \mathrm{hco}+\mathrm{o}$ \\
\hline 4 & $\mathrm{~h}+\mathrm{o} 2(+\mathrm{M})=\mathrm{ho} 2(+\mathrm{M})$ & 23 & $\operatorname{ch} 2+\mathrm{o} 2=\mathrm{co}+\mathrm{h} 2 \mathrm{o}$ & 42 & $\mathrm{c} 2 \mathrm{~h} 3+\mathrm{o} 2=\mathrm{c} 2 \mathrm{~h} 2+\mathrm{ho} 2$ \\
\hline 5 & $\mathrm{~h}+\mathrm{o} 2(+\mathrm{n} 2)=\mathrm{ho} 2(+\mathrm{n} 2)$ & 24 & $2 \mathrm{ch} 2=\mathrm{c} 2 \mathrm{~h} 2+2 \mathrm{~h}$ & 43 & $\mathrm{c} 2 \mathrm{~h} 3+\mathrm{oh}=\mathrm{c} 2 \mathrm{~h} 2+\mathrm{h} 2 \mathrm{o}$ \\
\hline 6 & $\mathrm{oh}+\mathrm{ho} 2=\mathrm{h} 2 \mathrm{o}+\mathrm{o} 2$ & 25 & $\mathrm{ch} 2+\mathrm{hcco}=\mathrm{c} 2 \mathrm{~h} 3+\mathrm{co}$ & 44 & $\mathrm{c} 2 \mathrm{~h} 3+\mathrm{ch} 3=\mathrm{c} 2 \mathrm{~h} 2+\mathrm{ch} 4$ \\
\hline 7 & $\mathrm{~h}+\mathrm{ho} 2=2 \mathrm{oh}$ & 26 & $\operatorname{ch} 2 o+h=h c o+h 2$ & 45 & $\mathrm{c} 2 \mathrm{~h} 2+\mathrm{oh}=\mathrm{ch} 2 \mathrm{co}+\mathrm{h}$ \\
\hline 8 & $h+h o 2=h 2+o 2$ & 27 & $\mathrm{hco}+\mathrm{o} 2=\mathrm{ho} 2+\mathrm{co}$ & 46 & $\mathrm{c} 2 \mathrm{~h} 2+\mathrm{o}=\mathrm{ch} 2+\mathrm{co}$ \\
\hline 9 & $h+h o 2=o+h 2 o$ & 28 & $\mathrm{hco}+\mathrm{M}=\mathrm{h}+\mathrm{co}+\mathrm{M}$ & 47 & $\mathrm{c} 2 \mathrm{~h} 2+\mathrm{o}=\mathrm{hcco}+\mathrm{h}$ \\
\hline 10 & $\mathrm{o}+\mathrm{ho} 2=\mathrm{o} 2+\mathrm{oh}$ & 29 & $\mathrm{hco}+\mathrm{oh}=\mathrm{h} 2 \mathrm{o}+\mathrm{co}$ & 48 & $\mathrm{c} 2 \mathrm{~h} 2+\mathrm{o} 2=\mathrm{hcco}+\mathrm{oh}$ \\
\hline 11 & $2 \mathrm{ho} 2=\mathrm{h} 2 \mathrm{o} 2+\mathrm{o} 2$ & 30 & $\mathrm{hco}+\mathrm{h}=\mathrm{co}+\mathrm{h} 2$ & 49 & $\mathrm{c} 2 \mathrm{~h} 2+\mathrm{h}(+\mathrm{M})=\mathrm{c} 2 \mathrm{~h} 3(+\mathrm{M})$ \\
\hline 12 & $2 \mathrm{oh}(+\mathrm{M})=\mathrm{h} 2 \mathrm{o} 2(+\mathrm{M})$ & 31 & $\mathrm{co}+\mathrm{oh}=\mathrm{co} 2+\mathrm{h}$ & 50 & $\operatorname{ch} 2 \mathrm{co}+\mathrm{h}=\mathrm{ch} 3+\mathrm{co}$ \\
\hline 13 & $\mathrm{~h} 2 \mathrm{o} 2+\mathrm{oh}=\mathrm{h} 2 \mathrm{o}+\mathrm{ho} 2$ & 32 & $\mathrm{c} 2 \mathrm{~h} 4+\mathrm{h}=\mathrm{c} 2 \mathrm{~h} 3+\mathrm{h} 2$ & 51 & $\operatorname{ch} 2 \mathrm{co}+\mathrm{oh}=\mathrm{hcco}+\mathrm{h} 2 \mathrm{o}$ \\
\hline 14 & $\mathrm{~h} 2 \mathrm{o} 2+\mathrm{h}=\mathrm{ho} 2+\mathrm{h} 2$ & 33 & $\mathrm{c} 2 \mathrm{~h} 4+\mathrm{oh}=\mathrm{c} 2 \mathrm{~h} 3+\mathrm{h} 2 \mathrm{o}$ & 52 & $\mathrm{~h} c \mathrm{co}+\mathrm{o}=\mathrm{h}+2 \mathrm{co}$ \\
\hline 15 & $\mathrm{~h} 2 \mathrm{o} 2+\mathrm{h}=\mathrm{oh}+\mathrm{h} 2 \mathrm{o}$ & 34 & $\mathrm{c} 2 \mathrm{~h} 4+\mathrm{o}=\mathrm{ch} 3+\mathrm{hco}$ & 53 & $\mathrm{hcco}+\mathrm{o} 2=\mathrm{hco}+\mathrm{co}+\mathrm{o}$ \\
\hline 16 & $\mathrm{~h} 2 \mathrm{o} 2+\mathrm{o}=\mathrm{oh}+\mathrm{ho} 2$ & 35 & $\mathrm{c} 2 \mathrm{~h} 4+\mathrm{o}=\mathrm{ch} 2 \mathrm{hco}+\mathrm{h}$ & 54 & hcco $+o 2=\mathrm{co} 2+$ hco \\
\hline 17 & $\operatorname{ch} 4+\mathrm{h}=\operatorname{ch} 3+\mathrm{h} 2$ & 36 & $\mathrm{c} 2 \mathrm{~h} 4+\mathrm{ch} 3=\mathrm{c} 2 \mathrm{~h} 3+\mathrm{ch} 4$ & 55 & $2 \mathrm{~h} c \mathrm{co}=\mathrm{c} 2 \mathrm{~h} 2+2 \mathrm{co}$ \\
\hline 18 & $\operatorname{ch} 4+\mathrm{oh}=\operatorname{ch} 3+\mathrm{h} 2 \mathrm{o}$ & 37 & $\mathrm{c} 2 \mathrm{~h} 4(+\mathrm{M})=\mathrm{c} 2 \mathrm{~h} 2+\mathrm{h} 2(+\mathrm{M})$ & & \\
\hline 19 & $\operatorname{ch} 3+\operatorname{ho} 2=\operatorname{ch} 4+\mathrm{o} 2$ & 38 & $\mathrm{c} 2 \mathrm{~h} 4(+\mathrm{M})=\mathrm{c} 2 \mathrm{~h} 3+\mathrm{h}(+\mathrm{M})$ & & \\
\hline
\end{tabular}

process and a more in-depth analysis of the detonation conditions and determining the rules of a single-channel WRC are first required.

To simplify the model and reduce simulation times, the following assumptions were made:

(a) Since 3D numerical simulations are time-consuming, $3 \mathrm{D}$ effects were neglected in this study and a 2D numerical simulation was adopted.

(b) A uniform premixed combustible mixture filled the WRC channel, and the relationship between pressure and density satisfied the state equations of an ideal gas.

(c) Heat exchange between the walls was ignored, and walls were assumed to be adiabatic.

(d) During the actual operating process, the channel moves whereas the hot-jet igniter remains stationary. To reduce the calculation burden, the channel was set as stationary, the hot-jet igniter was allowed to move, and movement of the channel was neglected.

The WRC model and related 2D simplified model are shown in Figure 11, in which the hot-jet is perpendicular to the channel, moving upwards, and ignites the premixed combustible mixture. The established simulation model was mainly focused on the combustion process in channel 2, whereas channels 1 and 3 were mainly used for simulating the environment in the WRC and not taken into account in subsequent analyses. Two sets of spoilers were set in the channel. The entire computational domain was meshed with a size of $0.4 \mathrm{~mm}$, and the wall surface was set as a boundary layer mesh. Laval nozzles were used to replace the heat flow ignition, and the hot-jet was simulated by assigning reasonable boundary conditions to the nozzles. An enlarged drawing of the nozzle structure and dimensions are presented in Figure 11.

The $2 \mathrm{D}$ calculation model of the single-channel WRC was mainly focused on ignition and flame propagation processes in the WRC. Using a premixed combustible fuel/air mixture, i.e., ignoring the filling process for the combustible fuel/air mixture in the WRC, means the exhaust of high-temperature burned gas can be neglected. Simplifying the 3D channel rotation as a $2 \mathrm{D}$ translation, as shown in Figure 11, the hotjet ignition is parallel to the channel and simultaneously moves in a direction perpendicular to the channel at a velocity of $85.032 \mathrm{~m} / \mathrm{s}$ (corresponding to the WRC of $4000 \mathrm{rpm}$ ). Channels 1 and 3 were mainly used for coordinating the hot-jet generator and producing continuous stable hot-jet flow. Channel 2 is where combustion mainly occurs and was filled with premixed fuel/air mixture under ambient temperature conditions. In channel 2, the mass fractions of $\mathrm{C}_{2} \mathrm{H}_{4}$, $\mathrm{O}_{2}$, and $\mathrm{N}_{2}$ were $0.169,0.579$, and 0.252 , respectively. The hot-jet generator was set as the "pressure inlet" at a pressure of 1.5 atmospheres and temperature of $2000 \mathrm{~K}$, and the chemical species were included the combustion products.

The combustion products of the hot-jet were determined using an adiabatic combustion phase equilibrium model. The initial temperature and pressure of ethylene were set as $298 \mathrm{~K}$ and $0.1 \mathrm{MPa}$, respectively. At the stoichiometric ratio, the combustion phase included combustion species in the equilibrium state. Concentrations of various combustion species are listed in Table 4.

Next, the effect of simplifying the chemical species of the hot-jet on the single-channel WRC was examined. Jets of 


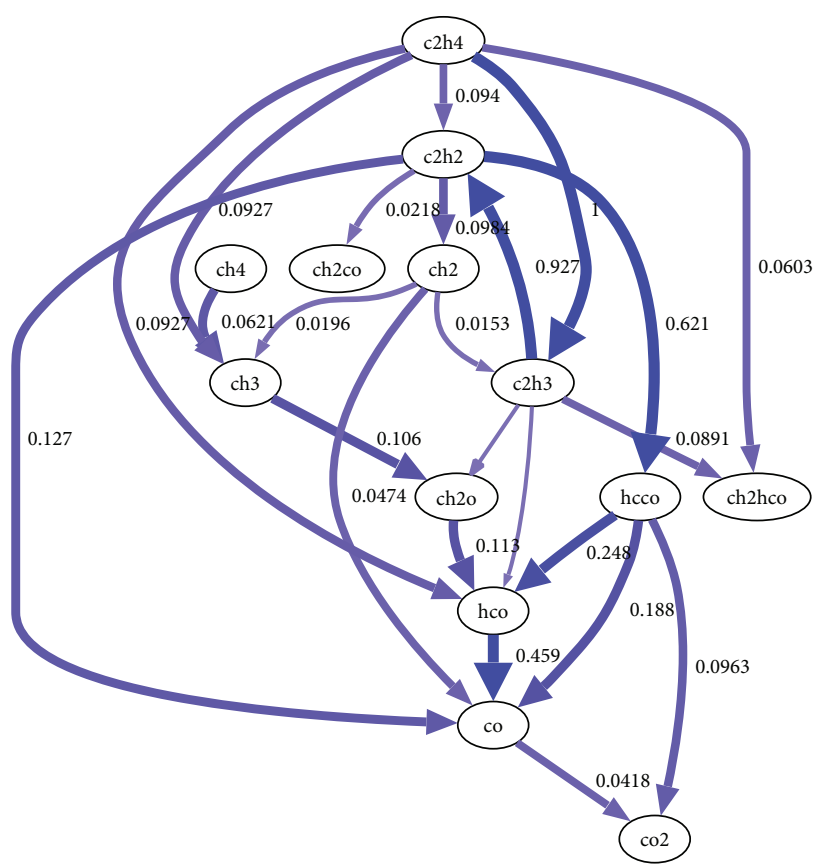

(a)

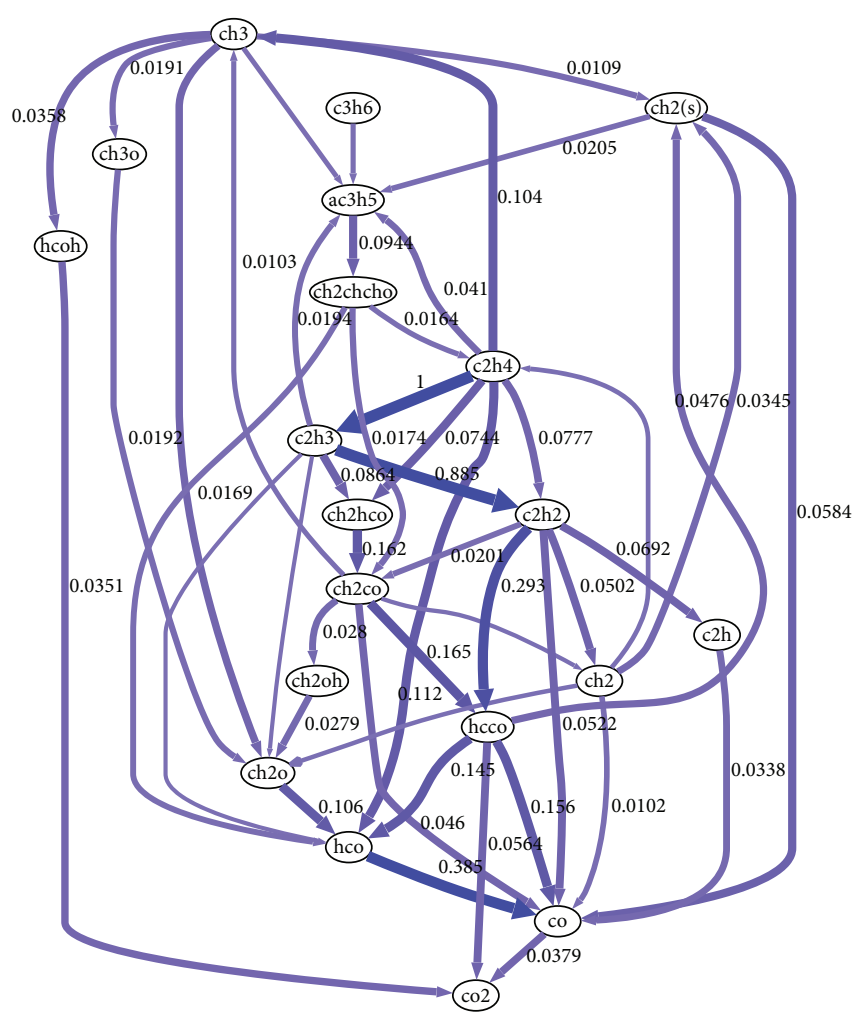

(b)

FIGURE 8: Analysis of reaction paths based on reaction mechanisms, (a) reduced mechanism and (b) detailed mechanism.

different chemical species were examined while simulation conditions remained unchanged. Operating conditions used in the simulations are listed in Table. 5.

Spoilers were also set in the WRC channel for strengthening turbulivity and increasing mixing in the channel, to promote the folding and deformation of flames, intensify heat release on the frontal flame surfaces, and accelerate propagation of flames [28]. However, adding spoilers could increase losses during flow, and the effects of characteristic parameters, such as the blockage ratio (BR) of the spoiler and combustion properties in the WRC and their variation, should be clarified. Simulations were conducted for different blockage ratios of spoilers while other conditions remained unchanged. Operating conditions used in the simulation are listed in Table 6.

4.3. Code Validation. Two methods are generally used for validating simulations. The first directly compares experimental data with simulation results under the same conditions, and the other uses a similar model to verify the reliability of the algorithm when experimental conditions cannot satisfy simulation requirements. It is difficult to directly use experiments for validating numerical simulation results of a WRC; therefore, reliability of the proposed method was indirectly validated. In theory, a WRC exhibits denotation combustion or near-denotation combustion. A relevant simulation method should be able to satisfy the simulation of denotation combustion. In addition, WRC channels always have short distances, and thus, realization of the transition from deflagration to denotation combustion is crucial. A 2D single-channel spark plug ignition model for simulating the denotation combustion process is most often used to validate the algorithm model, as shown in Figure 12. The red line denotes the outlet of the denotation tube, which was set as the "pressure outlet" and includes six groups of spoilers for shortening the DDT process. The remaining parts represent the wall surface. Before the simulation, the Patch assignment method was used to set the mass fractions of $\mathrm{C}_{2} \mathrm{H}_{4}, \mathrm{O}_{2}$, and $\mathrm{N}_{2}$ as $0.169,0.579$, and 0.252 , respectively. An excessive amount of oxidant was required due to the fact that denotation waves are hard to generate when the reaction between air and ethylene is directly used. The red star in Figure 12 represents the position where the spark plug was ignited instantaneously at high temperature.

Simulation results for pressure distributions in the central axis of the detonation tube at three different moments after stable denotation waves had already formed are displayed in Figure 13. The denotation wave velocities, denoted

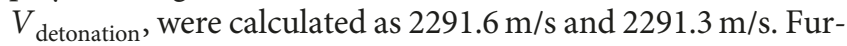
thermore, using Cantera, an open-source chemical reaction kinetics software, it was found that $V_{\mathrm{CJ}}=2326 \mathrm{~m} / \mathrm{s}$ [29]. The detonation wave velocity error may be as great as $1.5 \%$, which indicates that the error of ignition delay time during validation of reduced chemical reaction mechanism for ethylene combustion is acceptable. The simulation value of detonation wave velocity is quite close to the theoretical value, which suggests that the numerical simulation can accurately capture the denotation combustion process. Moreover, the reduced reaction mechanism of ethylene can sufficiently describe the characteristics of denotation 


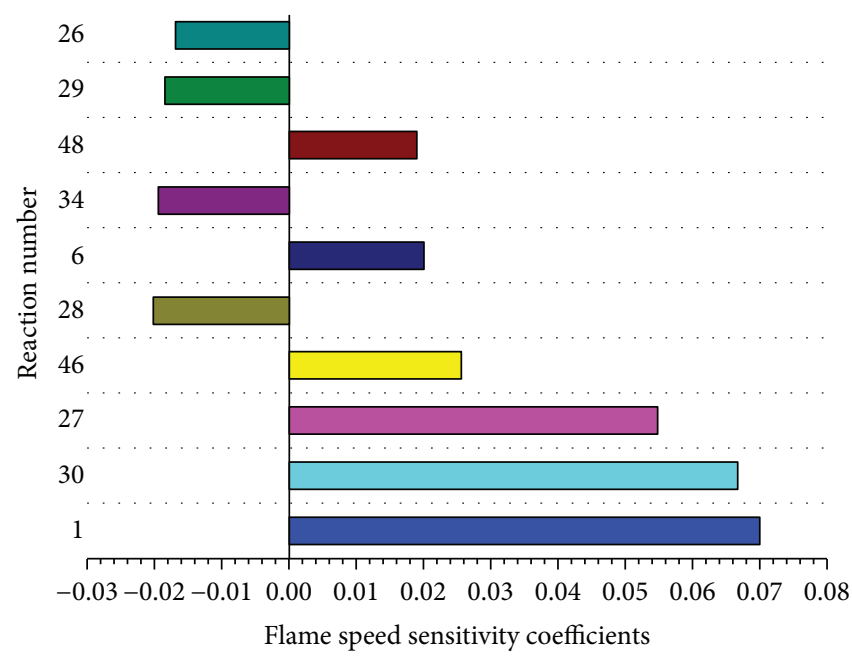

(a)

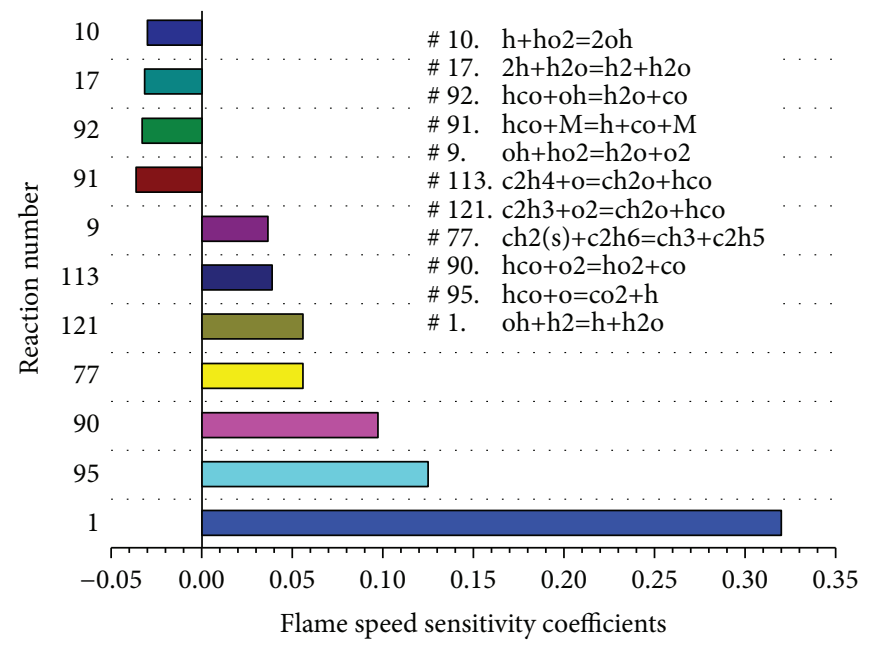

(b)

Figure 9: Results of sensitivity analysis to identify important chemical species, (a) reduced mechanism and (b) detailed mechanism.

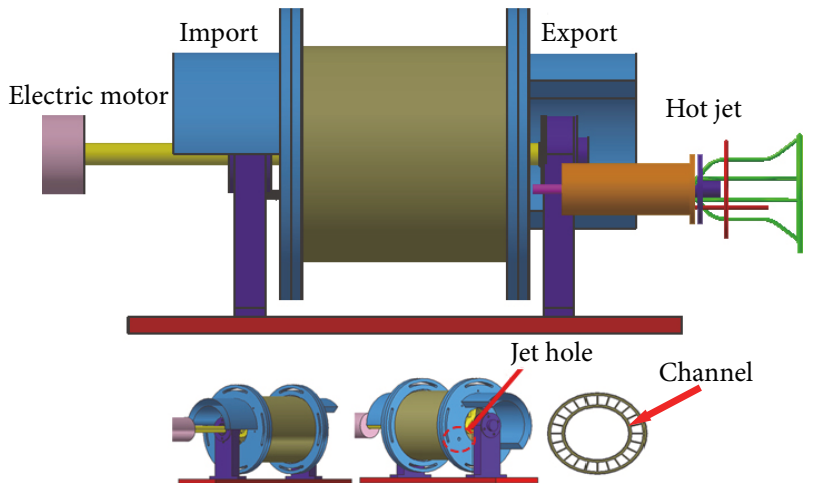

FIGURE 10: The physical model of full-scale WRC.

waves. The combustion properties in the WRC, such as interaction between shock wave and flame, were similar to the proposed simulation method, and the reaction mechanism can be adequately employed to simulate the combustion process in a WRC.

\section{Results and Discussion}

5.1. Ignition and Flame Propagation Process in WRC. The simplified propagation process for the wave and flames in the channel of WRC are shown in Figure 14, in which the flame distribution is characterized by the cloud chart of $\mathrm{OH}$ mass distribution. It can be observed that when $t=3.12 \mathrm{~ms}$, the hot-jet ignition comes into contact with the wave rotor channel and the fluid region is interconnected with the fluid region in the channel. Therefore, at this moment, fluid can freely pass through the channel and hot-jet enters the channel. At the channel entrance, $\mathrm{OH}$ radicals quickly appear, generated by combustion of the combustible mixture in the wave rotor channel, which is ignited by and partially carried by the hot-jet. Therefore, it can be confirmed that the premixed combustible fuel/air mixture in the channel is ignited by the hot-jet. The momentum carried by the hot-jet forms a jet shock wave while entering the wave rotor channel, and the region influenced by the jet shock waves is larger than the region affected by the jet energy. In other words, the shock wave is located in front of the flame surface and the leading edge of the $\mathrm{OH}$ mass fraction is referred to as the flame front surface. At $t=3.198 \mathrm{~ms}$, the flame profile shows that the flame front propagates in the circumferential direction. However, the axial propagation distance exceeds the radial propagation distance. Analyzing the motion state of the jet ignition, axial momentum of the hot-jet is greater than in the radial direction. As a result, the axial propagation distance of the flame is greater than in the radial direction, and the jet shock wave exhibits local stagnation upon hitting the upper wall surface of the channel, thereby increasing pressure at this position. At the same moment, the position of the pressure wave is in front of the flame front surface. At $t=$ $3.234 \mathrm{~ms}$, flames are distributed in a rectangular pattern and the axial propagation distance far exceeds the radial propagation distance. Along the radial direction, flames are reflected as the compression wave approaches the wall, thereby affecting the flame front and hindering the propagation of the flames. Furthermore, as the compression wave encounters obstacles, the jets are deflected and the propagation of flames in the axial direction stops, thus creating a straight flame front. At this moment, the compression wave passes over the obstacle and creates local stagnation behind the obstacle, which increases pressure at these positions and further expands the distance between the compression wave and flame front. At $t=3.264 \mathrm{~ms}$, the flame crosses the first obstacle and influence of the momentum of the hot-jet is weakened. Since the flame area is in the initial acceleration phase, propagation of the flame front is hindered and the flames expand after crossing the obstacle. Due to the existence of obstacles, the flame front clearly exhibits a lacerated pattern which decreases the flow area and accelerates fluid in the throat. The existence of obstacles causes the fluid to accelerate and increases turbulence, which is conductive to advancing the flame front, increasing the heat release area, 


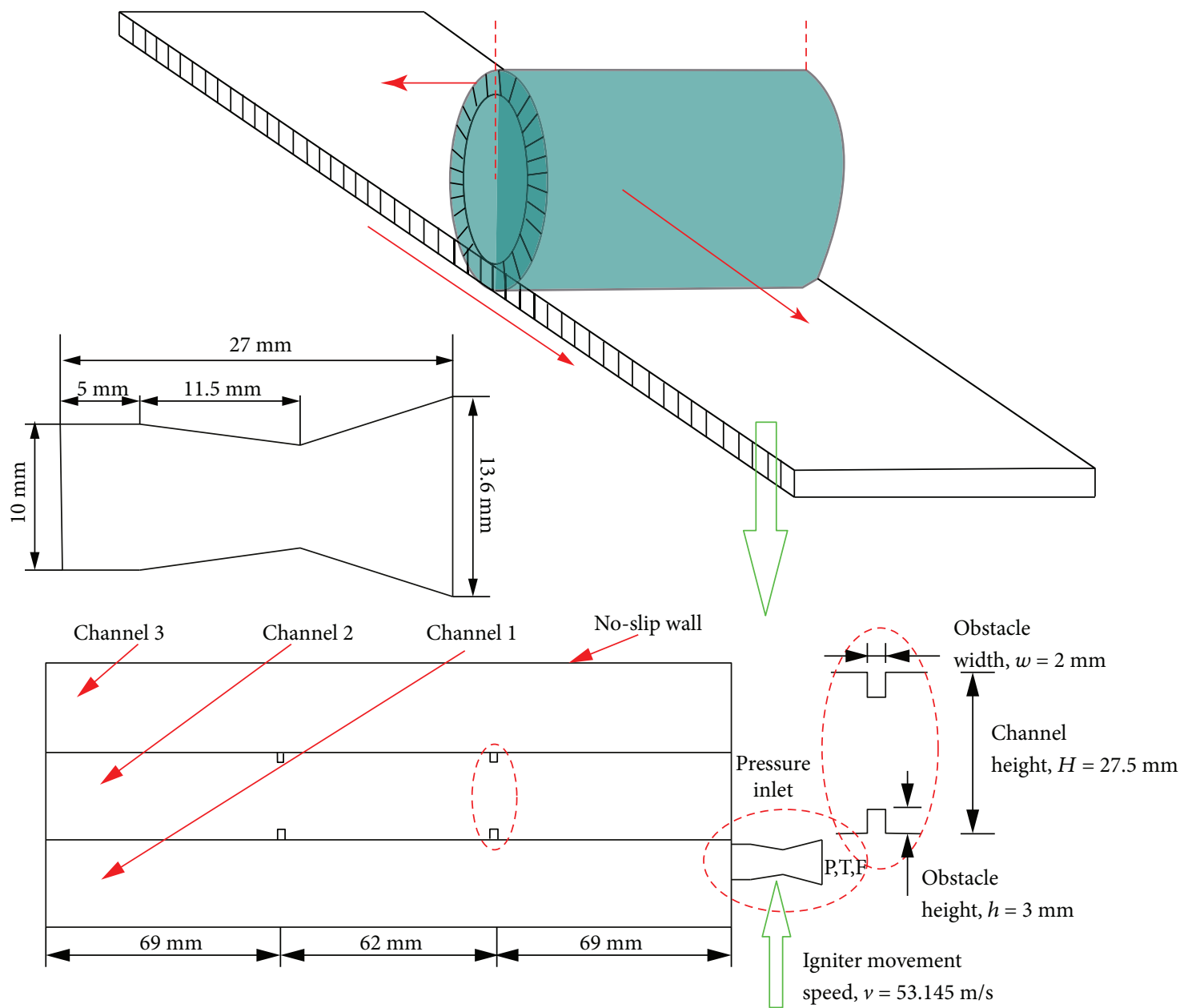

FIGURE 11: The simplified model of WRC.

TABLE 4: Species and related mass fractions during adiabatic equilibrium phase of ethylene.

\begin{tabular}{lccc}
\hline Component & Mass fraction & Component & Mass fraction \\
\hline $\mathrm{H}_{2}$ & 0.00334 & $\mathrm{O}$ & 0.0701 \\
$\mathrm{H}$ & 0.00343 & $\mathrm{OH}$ & 0.0629 \\
$\mathrm{CO}_{2}$ & 0.197 & $\mathrm{H}_{2} \mathrm{O}$ & 0.069 \\
$\mathrm{CO}$ & 0.197 & $\mathrm{O}_{2}$ & 0.127 \\
\hline
\end{tabular}

TABle 5: Parameters used to describe operating condition in simulation.

\begin{tabular}{lc}
\hline Operating condition & Species of hot-jet \\
\hline 1 & Combustion products \\
2 & $\mathrm{~N}_{2}$ \\
3 & $\mathrm{Ar}$ \\
\hline
\end{tabular}

and accelerating the propagation of flames [1]. As the radial flame approaches the wall, pressure between the flames and wall surface is further increased. At $t=3.234 \mathrm{~ms}$, the pressure wave crosses the obstacle and collides with the upper and
TABLE 6: Operating conditions used in simulations.

\begin{tabular}{lc}
\hline Operating conditions & Blockage ratio of the spoilers \\
\hline 1 & $\mathrm{BR}=0$ (no obstacle) \\
2 & $\mathrm{BR}=23.35 \%$ \\
3 & $\mathrm{BR}=31.13 \%$ \\
4 & $\mathrm{BR}=38.91 \%$ \\
\hline
\end{tabular}

lower wall surfaces leading to the formation of two highpressure regions (upper and lower). At $t=3.33 \mathrm{~ms}$, the flames are fully developed and both the flame front area and the heat release rate rapidly increase, which accelerates flame propagation and creates a positive feedback mechanism. At that time, the positions of the pressure wave and flame front drop, and pressure increases from $0.1 \mathrm{MPa}$ at $t$ $=3.198 \mathrm{~ms}$ to approximately $0.2 \mathrm{MPa}$. At $t=3.36 \mathrm{~ms}$, the pressure wave first encounters the obstacle while the flame is still behind it. After acceleration of the flow due to the obstacle, the distance between the pressure wave and flame front further increases. At that time, a local high-pressure region appears both in front of and behind the obstacle. The rear pressure region is generated by stagnation effects, 


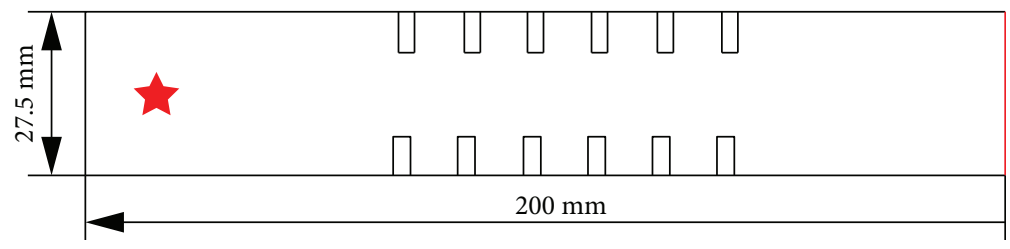

FIgURE 12: Algorithm validation model.

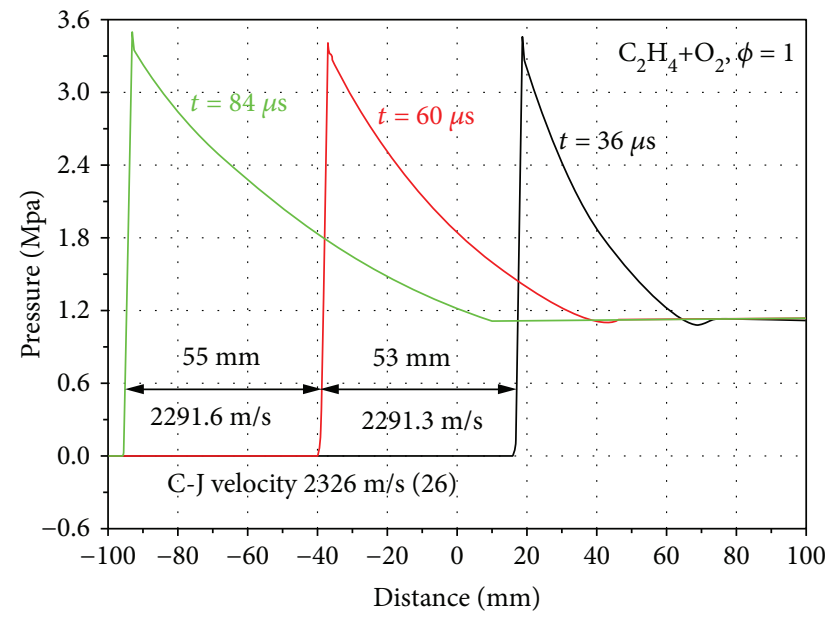

Figure 13: Pressure characteristic curves of denotation waves.

whereas the front region is generated by collision and reflection effects. At $t=3.39 \mathrm{~ms}$, the flame is rapidly accelerated by the obstacle, which decreases the distance between the flame front and the pressure wave. At that moment, the pressure reaches approximately $0.4 \mathrm{MPa}$. At $t=3.414 \mathrm{~ms}$, the local high-temperature region, generally referred to as the hightemperature hot spot, can be regarded as an overdrive denotation combustion. At $t=3.42 \mathrm{~ms}$, an arch shock wave with pressure of approximately $0.56 \mathrm{MPa}$ appears at the flame front; moreover, the shock wave and flame surface become partially coupled forming the denotation wave, but not fully developed. At $t=3.426 \mathrm{~ms}$, the partly coupled detonation wave rapidly spreads and fills the entire channel and two local high-pressure regions are formed at the intersection between the detonation wave and the wall surface. The two regions are generated by collisions between the detonation wave and wall surfaces during the development process. At the same time, the arch rate of the detonation wave gradually decreases and continues to decrease until $t=3.422 \mathrm{~ms}$. At $t=3.428 \mathrm{~ms}$, the arch detonation wave gradually transforms into a plane wave, during which time the detonation wave gradually becomes fully developed and complete waveflame coupling is realized. At $t=3.456 \mathrm{~ms}$, the detonation wave collides with the front wall and pressure is approximately $0.55 \mathrm{MPa}$.

In conclusion, the ignition and flame propagation process of the entire model can be described as detonation combustion. However, this is unlike conditions in a traditional detonation tube. One end of the traditional detonation tube is closed while the other end is open. In contrast, after ignition, both two ends of the WRC channel are closed suggesting that the channel can be regarded as a constantvolume combustor. A detonation engine makes use of the reaction thrust of the detonation wave, whereas a WRC mainly uses detonation combustion to form high-temperature and high-pressure burned gas, which also validates the WRC as an improved pressurized combustion device.

5.2. Effects of Hot-Jet with Different Species on Ignition and Combustion in WRC. The temperature cloud chart displaying the flame propagation process is presented in Figure 15, from which the entire flame propagation process can be clearly observed from $t=0.132 \mathrm{~ms}$ to $t=0.552 \mathrm{~ms}$, when the hot-jet enters the wave rotor channel 2 to when flame propagation is accelerated in the channel. From the simulation results, it can also be observed that the hot-jet of different chemical species greatly affects the combustion process in the WRC. Using the hot-jet of combustion products, detonation combustion is achieved in the WRC channel at $t=$ $0.552 \mathrm{~ms}$. However, detonation combustion does not occur when the hot-jets of $\mathrm{N}_{2}$ and $\mathrm{Ar}_{2}$ are used. Further, the flame propagation distance in combustion using the heated $\mathrm{N}_{2}$ jet far exceeds that in combustion using the heated $\mathrm{Ar}_{2}$ jet. The hot-jet of different species has significant effects on the ignition process in the WRC.

The ignition process of a combustible fuel/air mixture can be defined by its combustion products. Since the hot-jet of the combustion products includes $\mathrm{OH}$ radicals, $\mathrm{HO}_{2}$ radicals were used in this study to model radicals produced in combustion. Ignition processes in the WRC for hot-jets with different species are illustrated in Figure 16. A hot-jet of combustion products can directly ignite the premixed combustible fuel/air mixture in the channel, whereas hot-jets of $\mathrm{N}_{2}$ and $\mathrm{Ar}_{2}$ result in ignition delays. According to the simulation, ignition delay times for the heated $\mathrm{N}_{2}$ and $\mathrm{Ar}_{2}$ jets were approximately $0.138 \mathrm{~ms}$ and $0.246 \mathrm{~ms}$, respectively. Due to differences in the ignition delay times, when the hot-jet consists of the combustion products, initial flames propagate in an arc pattern; however, hot-jets of $\mathrm{N}_{2}$ and $\mathrm{Ar}_{2}$ result in ignition of the combustible fuel/air first around the vortex and flames, which then spread to the periphery. Since a lot of radicals directly participate in the combustion reaction, including $\mathrm{H}, \mathrm{OH}$, and $\mathrm{O}$ of the hot-jet of the combustion products, the reaction chain accelerates the initial reaction. Conversely, the hot-jets of $\mathrm{N}_{2}$ and $\mathrm{Ar}_{2}$ contain inert gases that are not involved in the reaction. Therefore, activation energy must be accumulated over a certain amount of time during the initial stage of the chemical reaction chain. The smaller specific heat associated with 


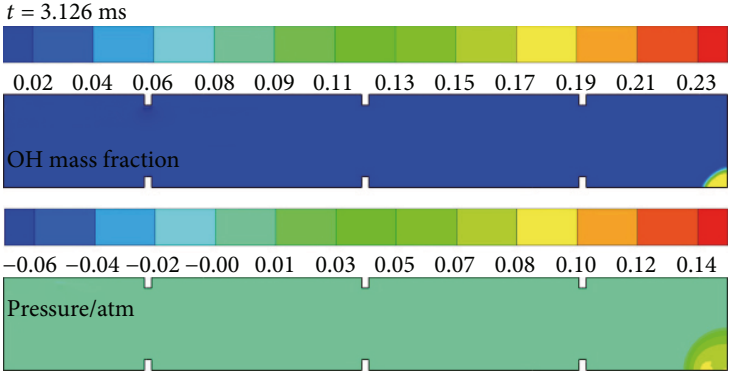

(a)

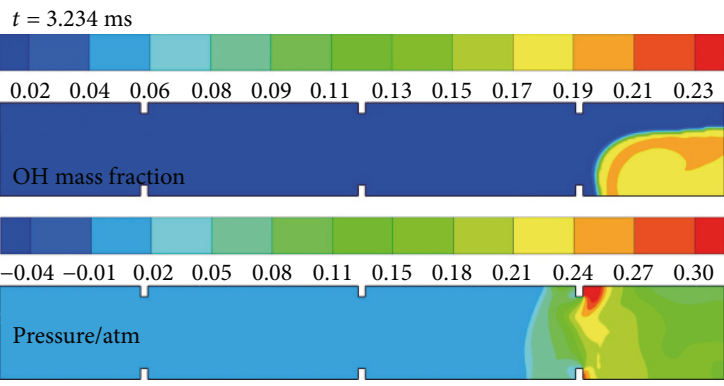

(c)

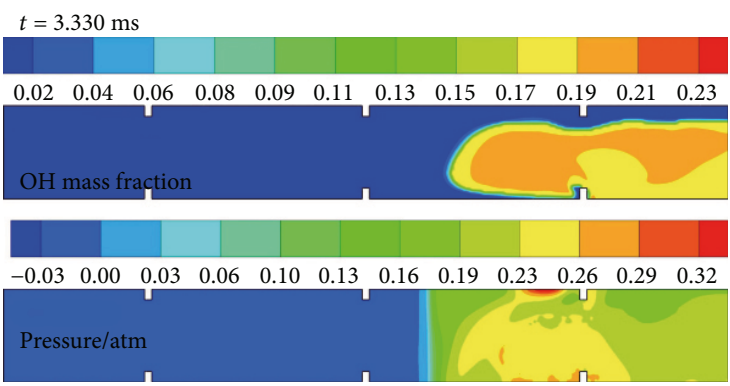

(e)

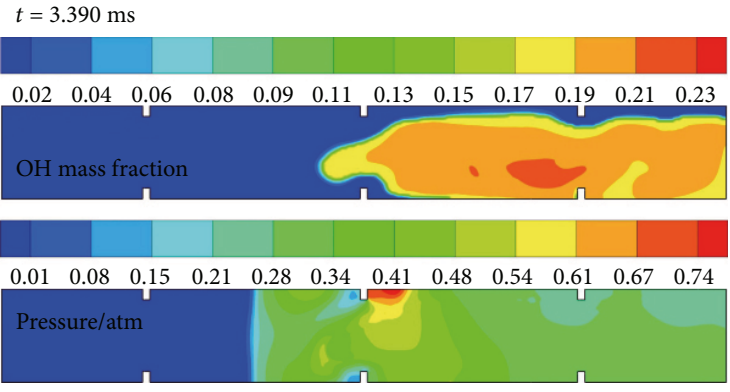

(g)

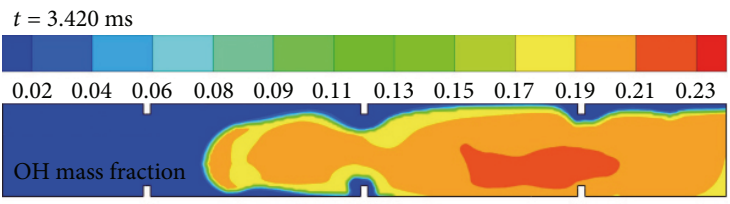

$\begin{array}{llllllllllll}0.43 & 0.91 & 1.39 & 1.86 & 2.34 & 2.82 & 3.29 & 3.77 & 4.25 & 4.72 & 5.20 & 5.67\end{array}$

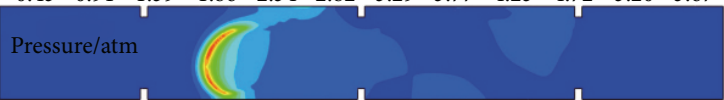

(i)

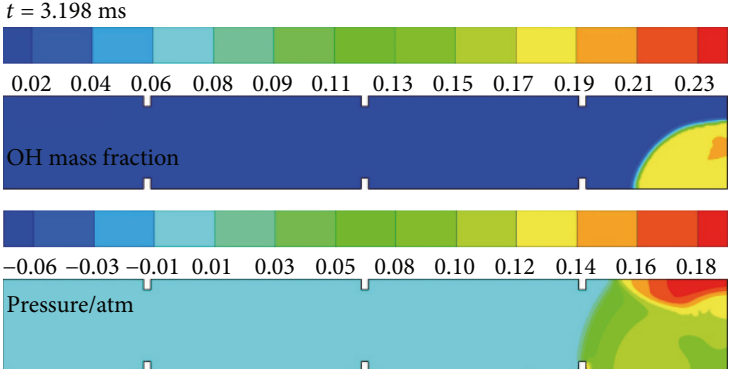

(b)

$t=3.264 \mathrm{~ms}$

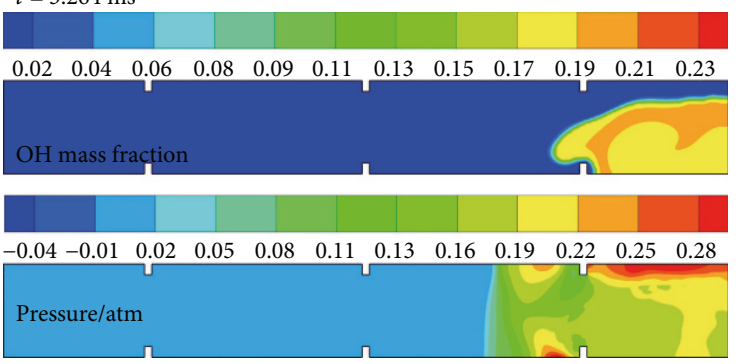

(d)

$t=3.360 \mathrm{~ms}$
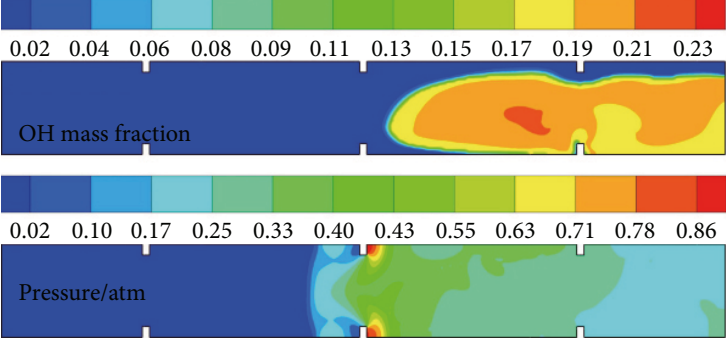

(f)

$t=3.414 \mathrm{~ms}$

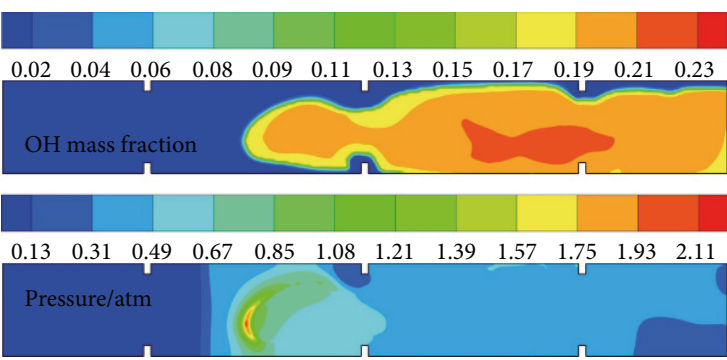

(h)

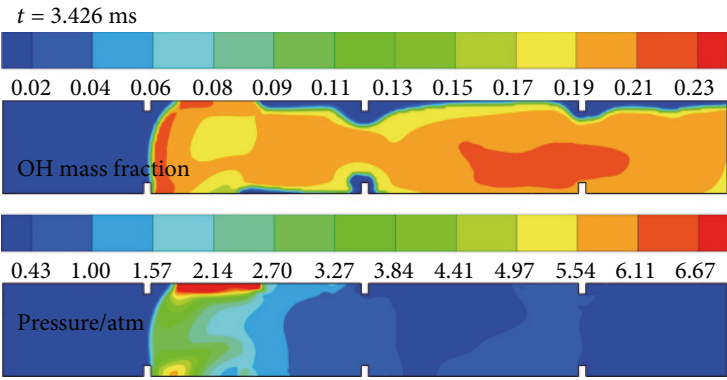

(j)

FIGURE 14: Continued. 


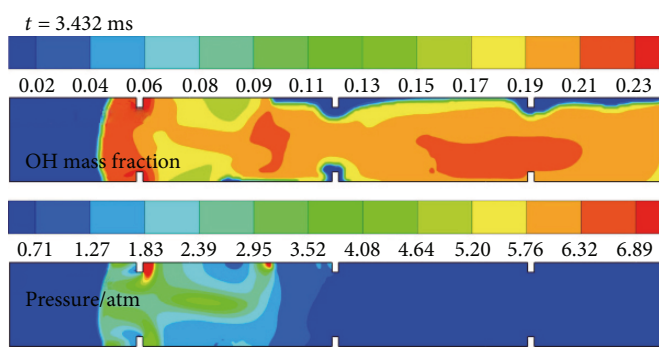

(k)

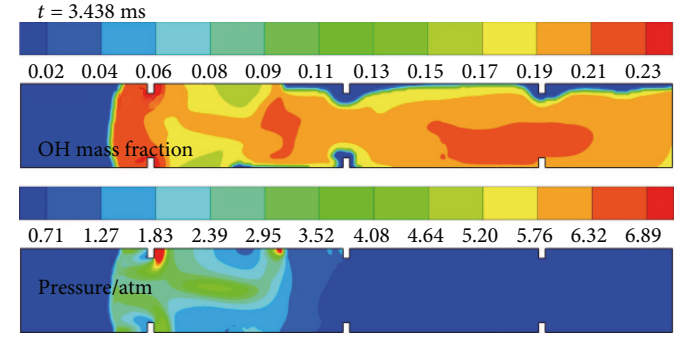

(l)

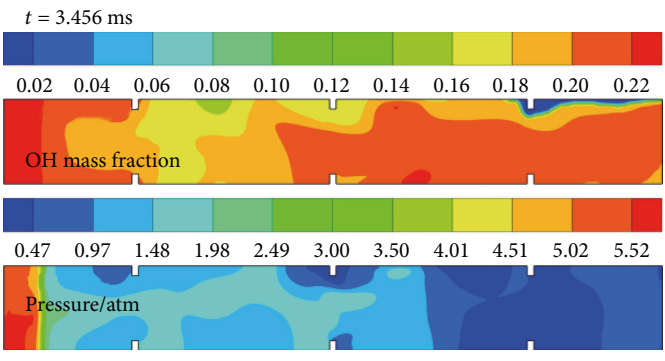

(m)

FIGURE 14: Detailed ignition and flame propagation processes in WRC.

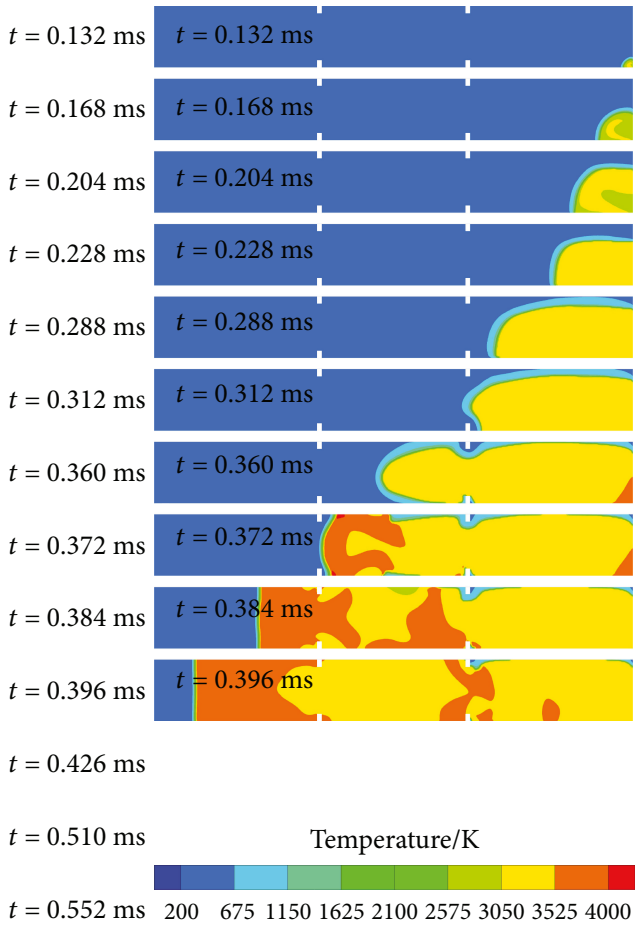

(a)

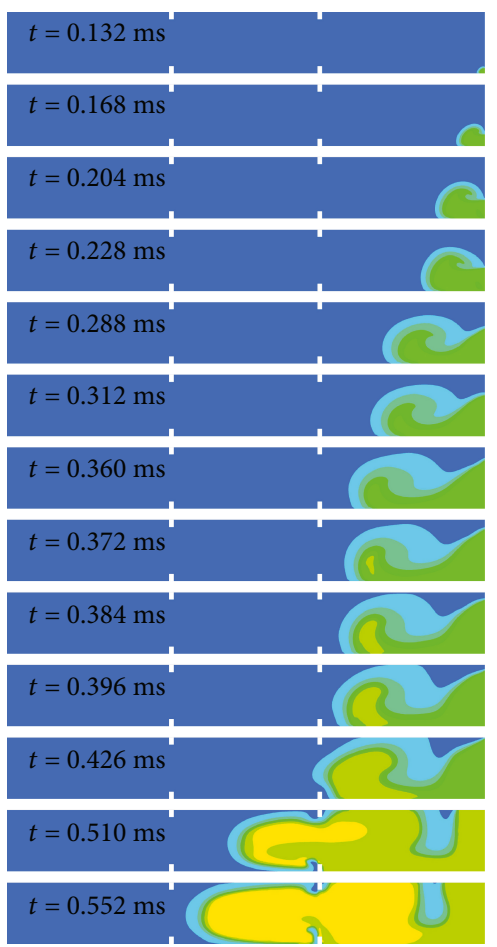

(b)

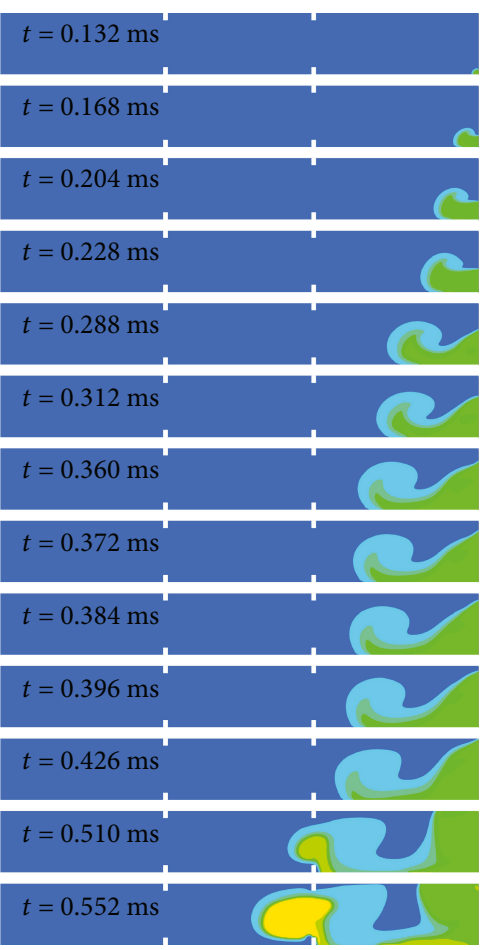

(c)

FIGURE 15: Simulated temperature cloud charts in WRC channel 2 when hot-jets of different species are used: (a) combustion products, (b) $\mathrm{N}_{2}$, and (c) $\mathrm{Ar}_{2}$.

$\mathrm{Ar}_{2}$ compared to $\mathrm{N}_{2}$ results in a slower energy release and longer ignition delay times.

Figure 17 shows flame propagation speed under the action of hot-jets with different chemical species. At $t=0.13$ $\mathrm{ms}$, the hot-jet of combustion products enters the wave rotor channel and immediately ignites the premixed combustible fuel/air mixture. Afterwards, the flame propagation speed increases steadily. At $t=0.375 \mathrm{~ms}$, the flame propagation 

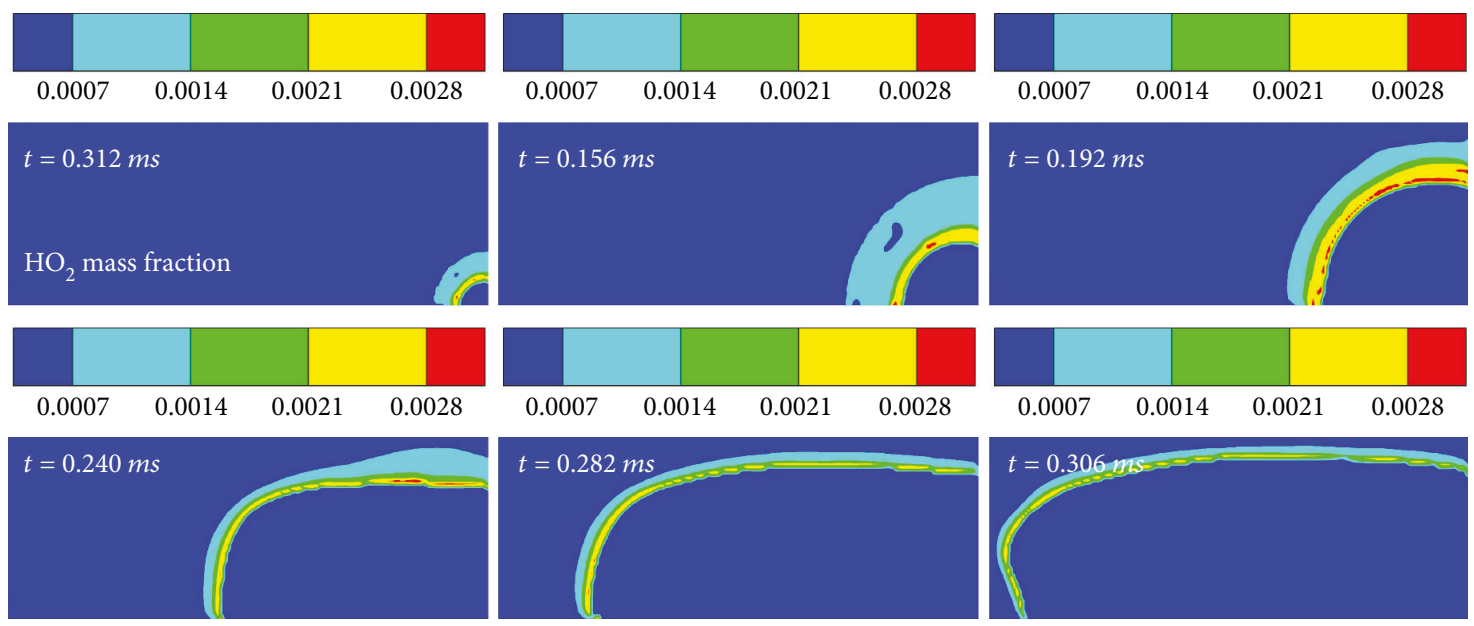

(a)
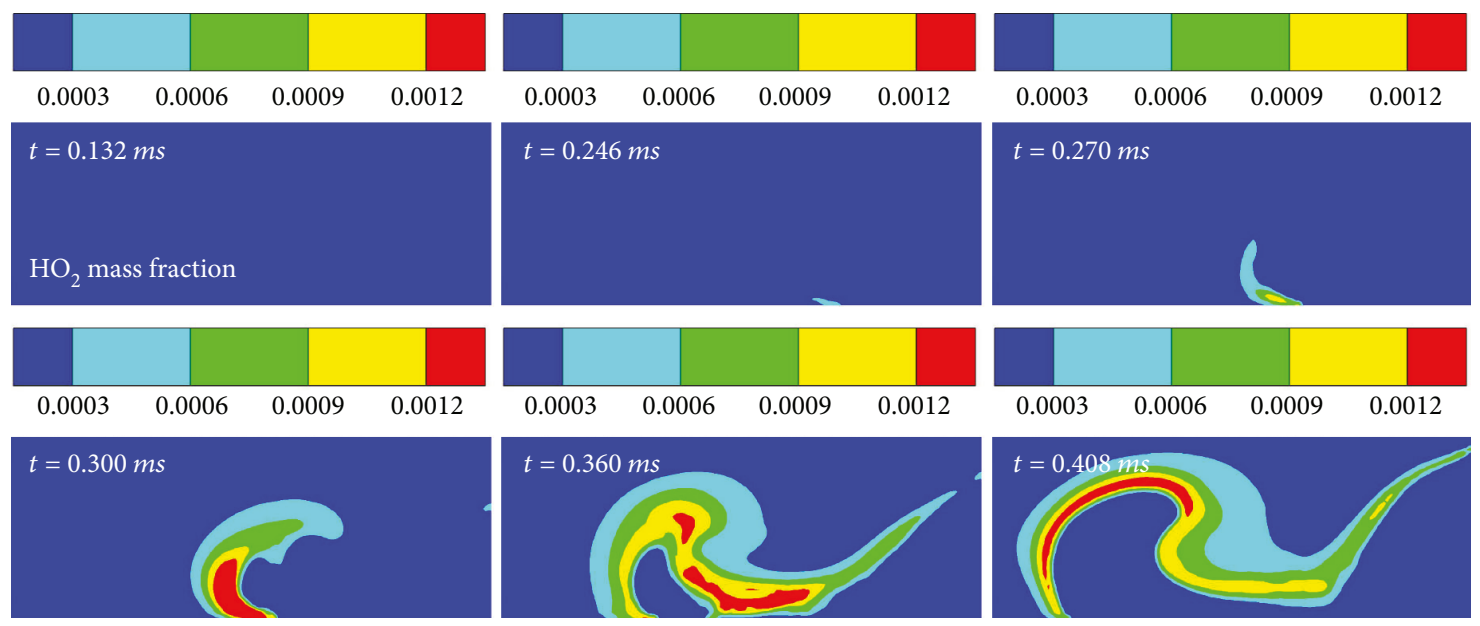

(b)
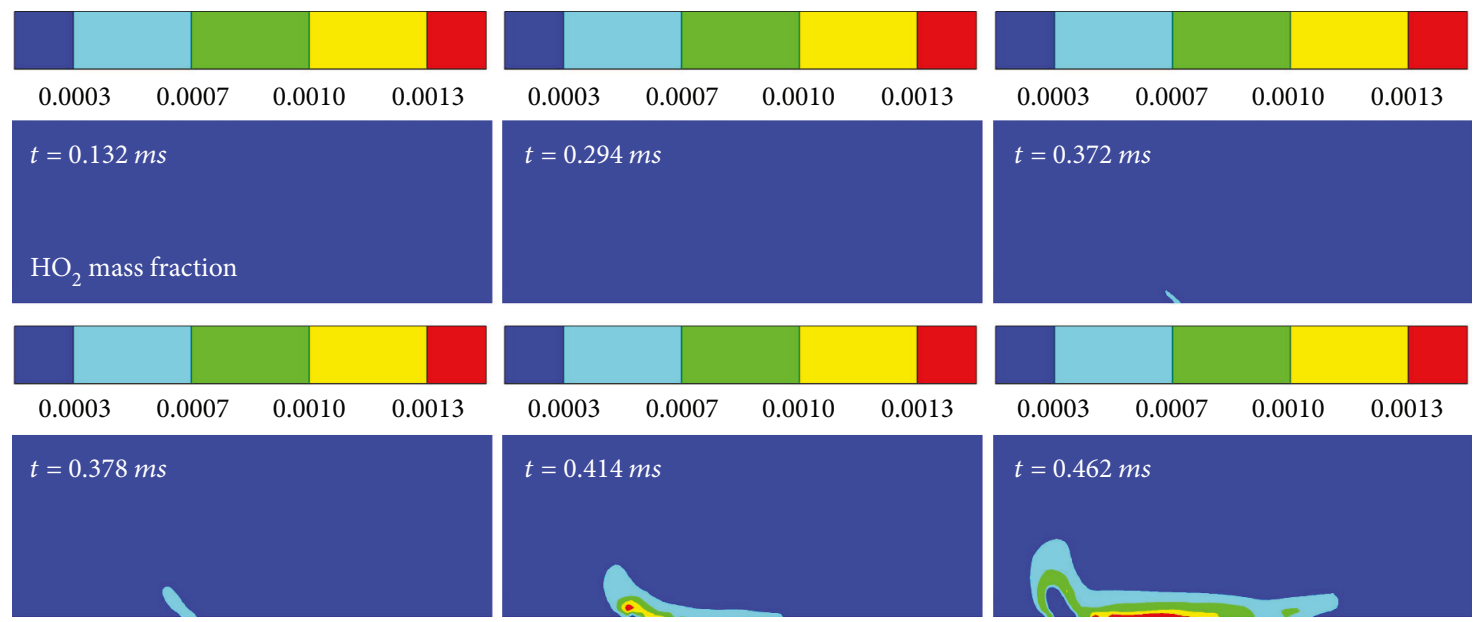

(c)

FIGURE 16: Cloud charts of $\mathrm{HO}_{2}$ concentration for hot-jets of different chemical species: (a) combustion products, (b) $\mathrm{N}_{2}$, and (c) Ar 2 .

speed reaches the theoretical value $\left(V_{\mathrm{CJ}}\right)$ and detonation combustion is triggered. Using a hot-jet consisting of the combustion products means the entire combustion process lasts only a short time. Hot-jets of $\mathrm{N}_{2}$ cause a delay of approximately $0.245 \mathrm{~ms}$, then the flame propagation is accelerated and flames spread during detonation combustion until $t=0.7 \mathrm{~ms}$. Hot-jets of $\mathrm{Ar}_{2}$ exhibit longer ignition delay times than do jets of $\mathrm{N}_{2}$. The entire flame propagation acceleration 


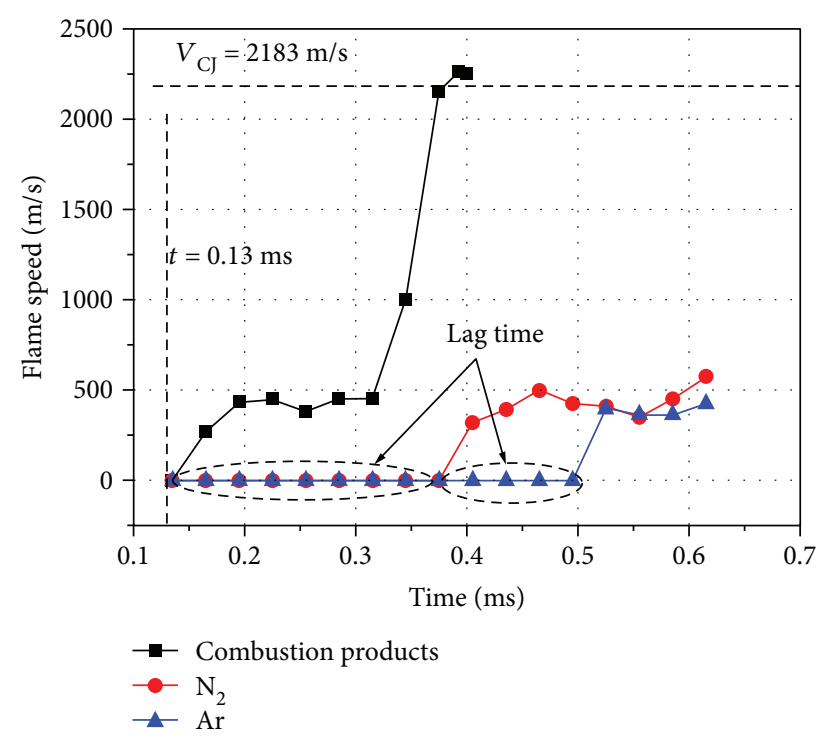

FIGURE 17: Variation of flame propagation speed with time.

process is similar to that of heated $\mathrm{N}_{2}$, jets and only a delay in the process is observed.

5.3. Effects of the Spoilers with Blockage Ratio on Combustion Characteristics of WRC. As shown in Figure 14, the propagation of the wave and flames shows similar trends under operating conditions of $\mathrm{BR}=23.35 \%, \mathrm{BR}=31.13 \%$, and $\mathrm{B}$ $\mathrm{R}=38.91 \%$. However, using operating conditions of $\mathrm{BR}=0$, the wave and flames exhibit different propagation rules. The wave propagation process under operating conditions of $\mathrm{BR}=0$ is displayed in Figure 18 from $t=3.09 \mathrm{~ms}$ to $t=$ $3.912 \mathrm{~ms}$, from when the hot-jet enters the WRC channel to when stable detonation waves are formed. In contrast to wave propagation characteristics in the WRC with spoilers, waves are propagated in a planar pattern. Moreover, at $t=3.492$ $\mathrm{ms}$, the compression wave spreads to the end of the channel and the flame surface remains in the middle of the channel. At $t=3.528 \mathrm{~ms}$, the compression wave is reflected by the wall surface and pressure increases from $0.2 \mathrm{MPa}$ to $0.8 \mathrm{MPa}$. After reflection, the compression undergoes expansive back propagation and pressure of the wave decreases. After, the flames are stagnated.

Flame propagation is further hindered by both the reflected compression wave and small concentrations of combustible fuel/air mixture in front of the flame. At $t=$ $3.708 \mathrm{~ms}$, the reflected compression wave encounters the wall on the inlet duct and is reflected, and pressure of the compression wave rises to $1.0 \mathrm{MPa}$. At $t=3.906 \mathrm{~ms}$, the compression wave encounters the flame surface and is partly coupled, and a strong arch shock wave is formed in front of the flame. At $t=3.912 \mathrm{~ms}$, the wave and flames are completely coupled forming a planar detonation wave.

Figure 19 displays the statistical variation of the wave and flame propagation when spoilers with different blockage ratios were used. More specifically, variation of wave and flame propagation velocities over time, variations of the wave and flame velocities with position, and variation of the wave and flame positions with time are presented. It can be observed that under operating conditions of $\mathrm{BR}=0$, the wave propagation speed is always greater. In general, during the propagation process, flames are first accelerated, then decelerated, and finally accelerated again. Combining the results presented in Figures 14 and 18, it can be concluded that flame propagation speed is significantly affected by jets at the beginning since in the initial stage, the flames are rapidly accelerated. Afterwards, action of the hot-jet is weakened, and the flame propagation speed decreases briefly and thereafter increases. Furthermore, the compression wave in front of the flames exhibits similar propagation rules, whereby propagation speed first increases, then drops, and finally increases. Based on the relationship between the position of the wave and flames with time, it can be observed that the distance between the wave and flames increases with time. Throughout the entire propagation period, the maximum flame propagation speed reaches up to $420 \mathrm{~m} / \mathrm{s}$, suggesting that rapid combustion occurs in the WRC channel. The flame and wave propagation properties under operating conditions of $\mathrm{BR}=23.35 \%, \mathrm{BR}=31.13 \%$, and $\mathrm{BR}=38.91 \%$ are similar. Under these operating conditions, flames catch up to the shock wave and complete coupling is achieved. The maximum wave and flame propagation speeds under operating condition of $\mathrm{BR}=23.35 \%$ are greater than the values under operating conditions of $\mathrm{BR}=31.13 \%$ and $\mathrm{BR}=38.91$ $\%$. This is due to the fact that under operating conditions of $\mathrm{BR}=23.35 \%$, the coupling position between the shock wave and flames occurs around spoiler 3, thereby accelerating flame propagation. Under operating conditions of $\mathrm{BR}=$ $31.13 \%$ and $\mathrm{BR}=38.91 \%$, coupling between the shock wave and flames occurs in front of spoiler 3 , and flame propagation speeds are close to theoretical values $\left(V_{\mathrm{CJ}}\right)$. Under operating conditions of $\mathrm{BR}=38.91 \%$, the shock wave and flames are coupled early and attenuation of the detonation wave is clearly observed; moreover, propagation of the detonation wave gradually becomes stable. Thus, a number of conclusions can be drawn. First, the existence of turbulent flow results in coupling between the shock wave and flames in a short time and distance. Since both ends of the wave rotor channel are closed, the shock wave can be coupled to the flame surface during backward and forward propagation even when no spoilers are used. However, the coupling position is always located at the end of the channel. Second, as the blockage ratio of the spoilers increases, the coupling position between the shock wave and flames gradually advances.

\section{Conclusions}

In this study, the reduced chemical reaction mechanism of ethylene based on the LLNL N-Butane mechanism was gained, which included 23 species and 55 elementary reaction steps. Then, ignition delay time, flame propagation speed, and molar fractions of the reactants and main products were simulated based on the reduced mechanism. Overall, numerical results using the reduced mechanism were consistent with data derived from the detailed mechanism, thus verifying the effectiveness of the reduced mechanism. Furthermore, numerical simulations were performed 


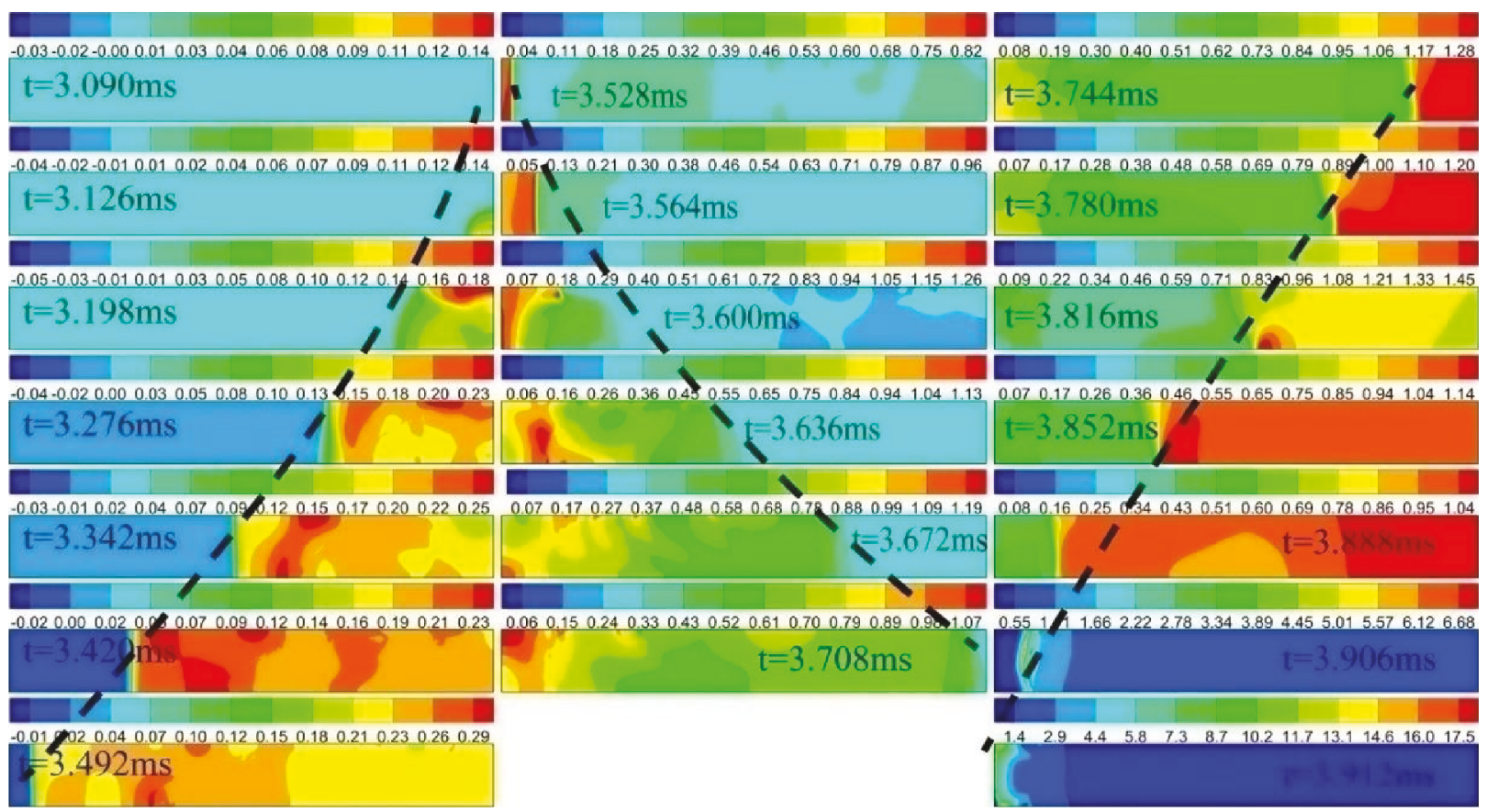

(a)

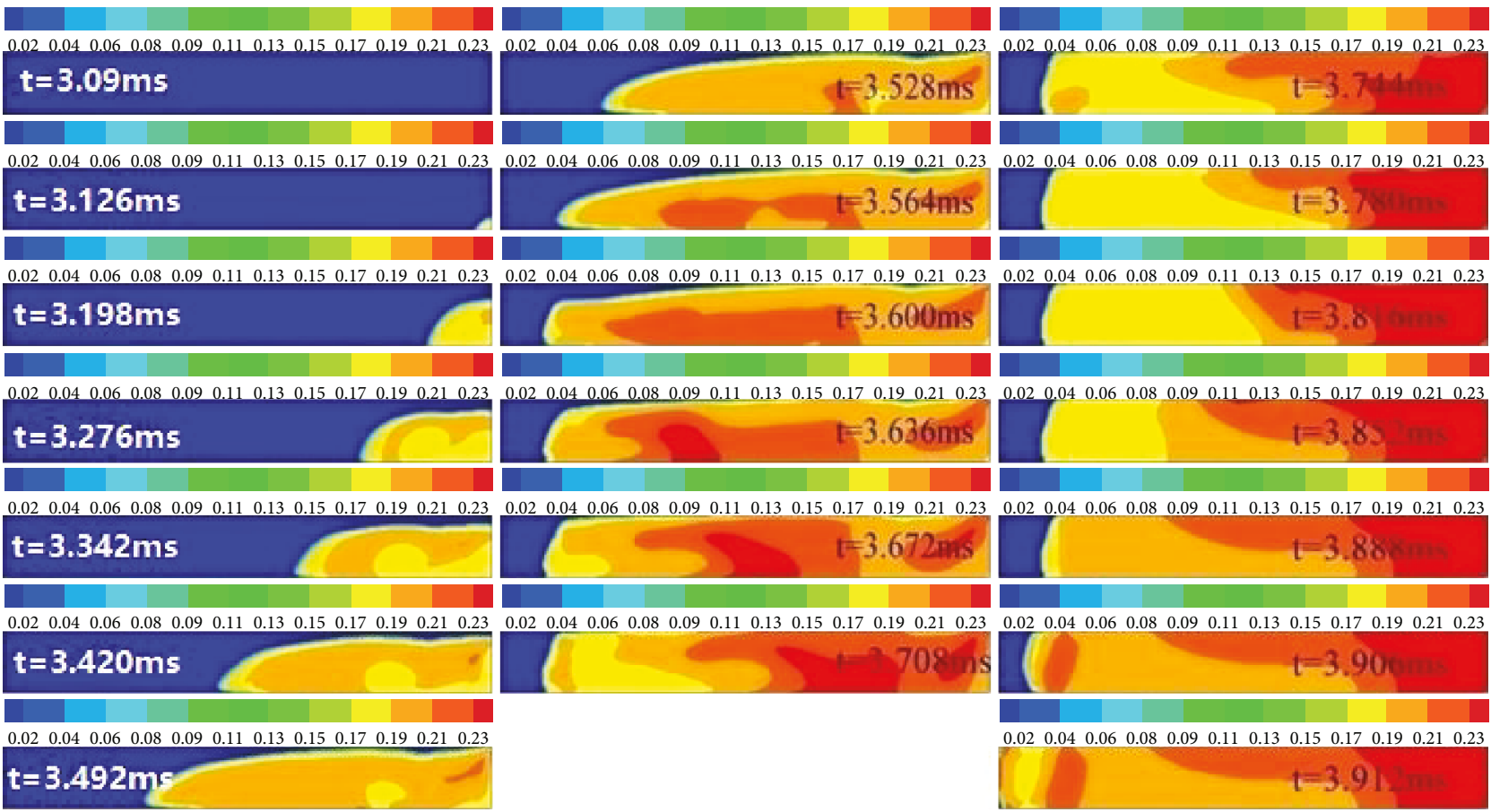

(b)

FIGURE 18: Propagation of wave and flame in the WRC channel under operating conditions of BR =0: (a) propagation of wave and (b) propagation of flame.

on the combustion process in the WRC using the reduced mechanism and EDC combustion model to investigate the effects of hot-jets with different species and spoilers with different blockage ratios on the ignition and propagation properties in the channel of WRC. Simplifying hot-jets of combustion products as hot-jets of inert gases, ignition delay time increases, whereas premixed combustible fuel/ air mixture is directly ignited when the hot-jets of the combustion products are used. The existence of spoilers achieves coupling between wave and flames within a short time and distance, and coupling position is also advanced with the blockage ratio of the spoiler increasing. 

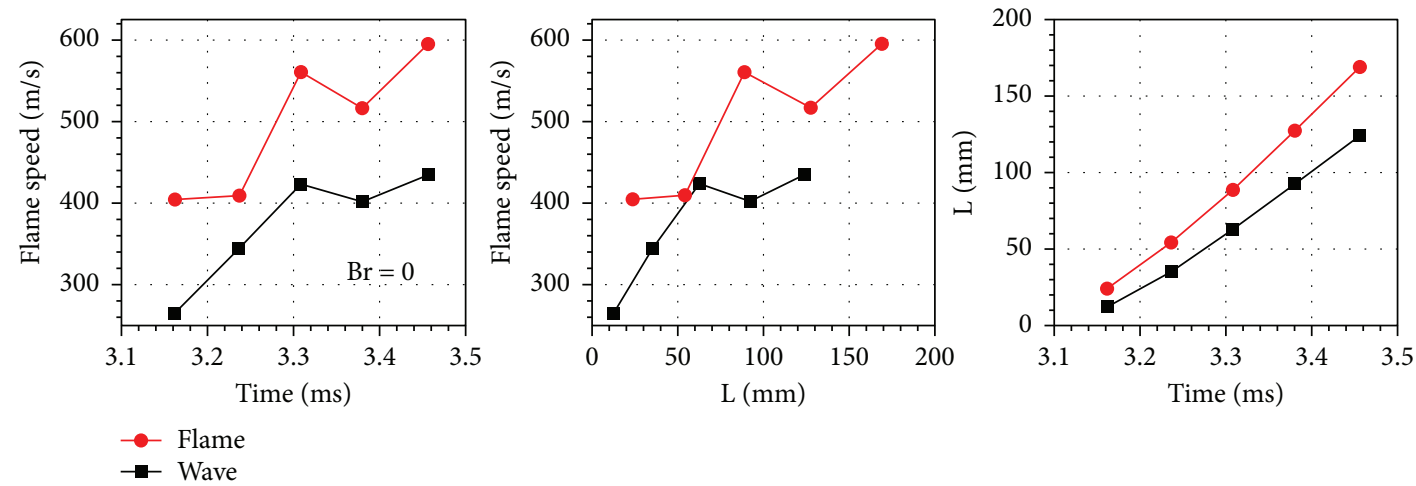

- Flam

(a)
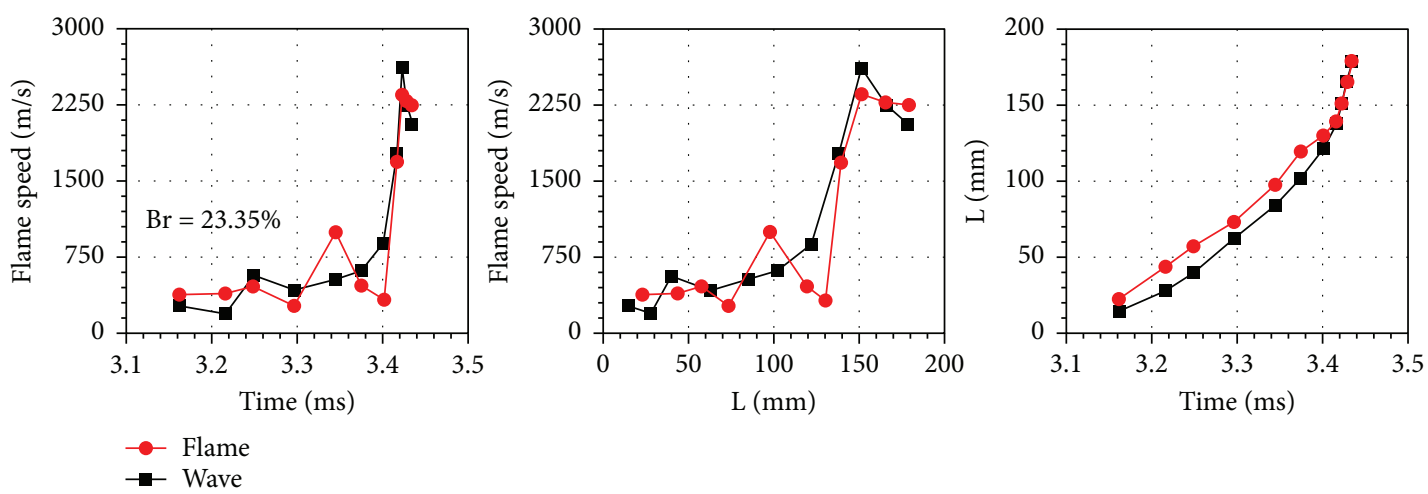

- Wave

(b)
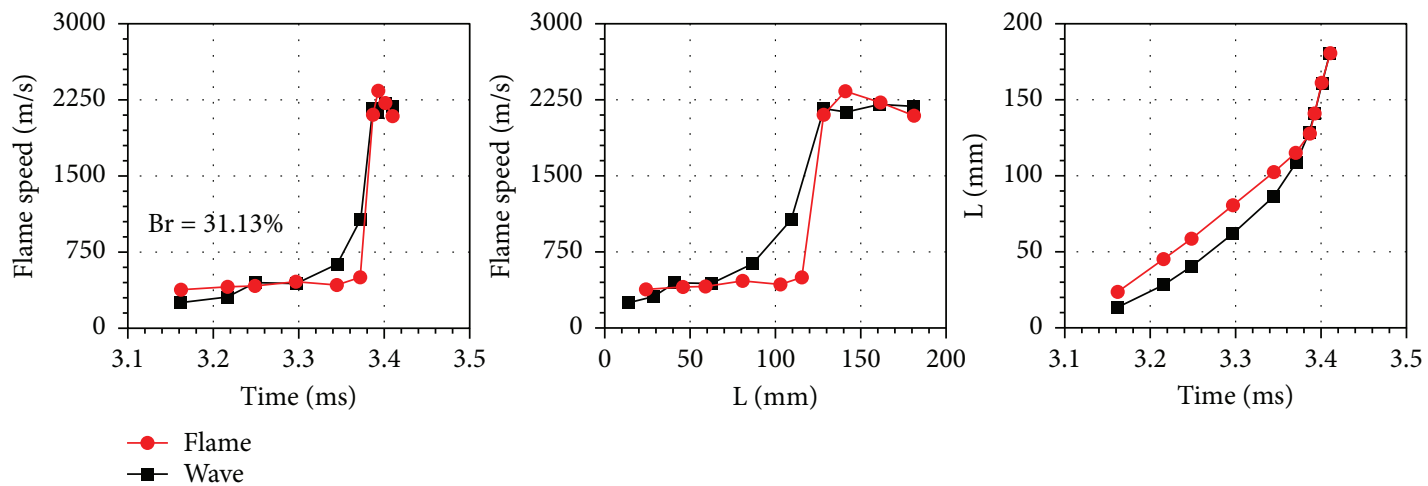

$\rightarrow$ - Wave

(c)
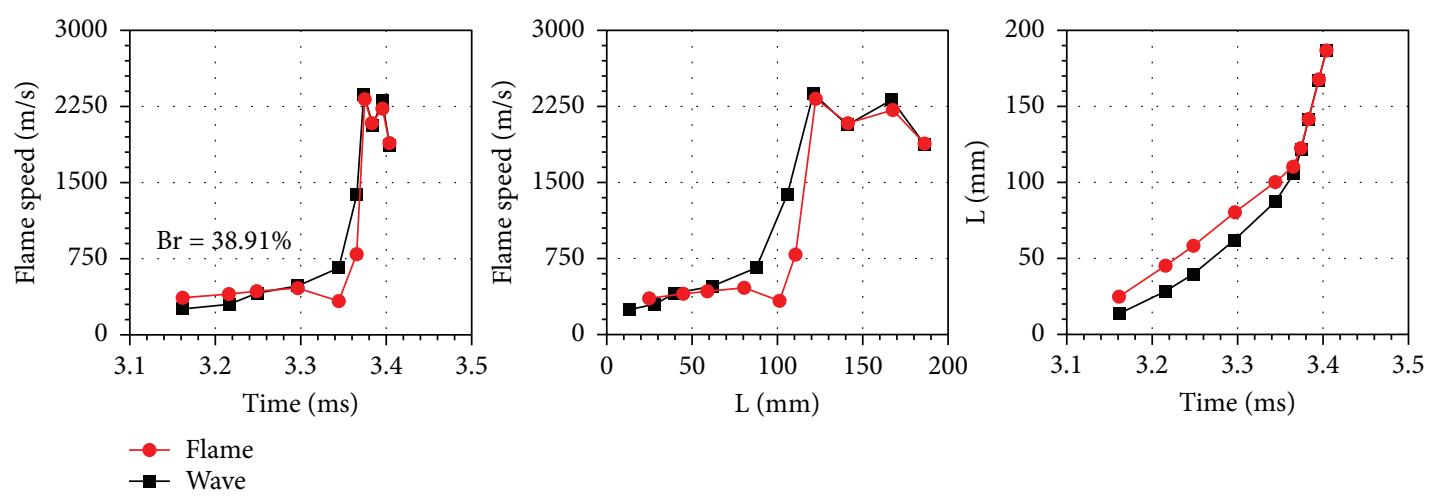

(d)

Figure 19: Propagation of shock wave and flames using spoilers with different blockage ratios. 


\section{Data Availability}

The data used to support the findings of this study are available from the corresponding author upon request.

\section{Conflicts of Interest}

The authors declare that they have no conflicts of interest.

\section{Acknowledgments}

This work was supported by "the National Natural Science Foundation of China,” NO. 51476077.

\section{References}

[1] M. R. Nalim and K. Jules, "Pulse combustion and wave rotors for high-speed propulsion engines," in 8th AIAA International Space Planes and Hypersonic Systems and Technologies Conference, Norfolk, VA, USA, April 1998.

[2] M. R. Nalim, "Assessment of combustion modes for internal combustion wave rotors," Journal of Engineering for Gas Turbines and Power, vol. 121, no. 2, pp. 265-271, 1999.

[3] P. Akbari, M. R. Nalim, and P. H. Snyder, "Numerical simulation and design of a combustion wave rotor for deflagrative and detonative propagation," in 42nd AIAA/ASME/SAE/ASEE Joint Propulsion Conference \& Exhibit, Sacramento, CA, USA, July 2006.

[4] A. Karimi, M. Rajagopal, and R. Nalim, "Traversing hot-jet ignition in a constant-volume combustor," Journal of Engineering for Gas Turbines and Power, vol. 136, no. 4, article 041506, p. 8, 2014.

[5] G. E. Welch, S. M. Jones, and D. E. Paxson, "Wave-rotorenhanced gas turbine engines," Journal of Engineering for Gas Turbines and Power, vol. 119, no. 2, pp. 469-477, 1997.

[6] T. Elharis, S. Wijeyakulasuriya, M. Nalim, and Y. Matsutomi, "Analysis of deflagrative combustion in a wave-rotor constant-volume combustor," in 49th AIAA Aerospace Sciences Meeting including the New Horizons Forum and Aerospace Exposition, Orlando, FL, USA, January 2013.

[7] J. Li, E. Gong, L. Yuan, W. Li, and K. Zhang, "Experimental investigation on pressure rise characteristics in an ethylene Fuelled wave rotor combustor," Energy \& Fuels, vol. 31, no. 9, pp. 10165-10177, 2017.

[8] L. Jianzhong, G. Erlei, and L. Wei, "Investigation on combustion properties in simplified wave rotor constant volume combustor," in 21st AIAA International Space Planes and Hypersonics Technologies Conference, Xiamen, Fujian, March 2017.

[9] P. Chinnathambi, A. Karimi, M. Rajagopal, and M. Nalim, Experimental Study of Traversing Hot-Jet Ignition of Lean Hydrocarbon-Air Mixtures in a Constant-Volume Combustor, 13, 8th US National Meeting, Combustion Institute, 2014.

[10] A. Karimi, M. Rajagopal, and R. Nalim, "Traversing hot-jet ignition in a constant-volume combustor," in ASME Turbo Expo 2013: Turbine Technical Conference and Exposition, San Antonio, TX, USA, June 2013.

[11] H. Wang, X. You, A. V. Joshi et al., "USC Mech Version II: High-Temperature Combustion Reaction Model of H2/CO/
C1-C4 Compounds," May 2007, http://ignis.usc.edu/USC_ Mech_II.htm.

[12] J. Y. Chen, Y. H. Chen, and Y. Choi, "Development and validation of isooctane skeletal mechanisms based on LLNL detailed mechanism," International Journal of Vehicle Design, vol. 46, no. 1, pp. 128-138, 2008.

[13] A. A. Konnov, Detailed Reaction Mechanism for Small Hydrocarbons Combustion, Release 0.5, 2000.

[14] A. K. Liu, S. H. Li, F. Wang, and X. Y. Li, "Reduction of ethylene combustion kinetic mechanism," Journal of Propulsion Technology, vol. 1, pp. 142-148, 2015.

[15] H. Yu, Z. Chen, and X. L. Gou, "Reduction mechanism for the oxidation of ethene," Journal of Engineering Thermophysics, vol. 34, no. 2, pp. 376-379, 2013.

[16] Y. D. Zhang, Simulation Study on Simplification of Chemical Kinetics Model and Soot Formation for Ethylene Flames, A Doctoral Dissertation from Huazhong University of Science and Technology, 2011.

[17] M. Frenklach, T. Bowman, and G. Smith, GRI-Mech Home Page, 1999, http://combustion.berkeley.edu/gri-mech/ index.html.

[18] “Diego Mechanism," http://web.eng.ucsd.edu/mae/groups/ combustion/mechanism.html.

[19] D. M. Kalitan, J. M. Hall, and E. L. Petersen, "Ignition and oxidation of ethylene-oxygen-diluent mixtures with and without silane," Journal of Propulsion and Power, vol. 21, no. 6, pp. 1045-1056, 2005.

[20] J. A. Baker and G. B. Skinner, "Shock-tube studies on the ignition of ethylene-oxygen-argon mixtures," Combustion and Flame, vol. 19, no. 3, pp. 347-350, 1972.

[21] G. Jomaas, X. L. Zheng, D. L. Zhu, and C. K. Law, "Experimental determination of counterflow ignition temperatures and laminar flame speeds of $\mathrm{C}_{2}-\mathrm{C}_{3}$ hydrocarbons at atmospheric and elevated pressures," Proceedings of the Combustion Institute, vol. 30, no. 1, pp. 193-200, 2005.

[22] T. Hirasawa, C. J. Sung, A. Joshi, Z. Yang, H. Wang, and C. K. Law, "Determination of laminar flame speeds using digital particle image velocimetry: binary fuel blends of ethylene, nbutane, and toluene," Proceedings of the Combustion Institute, vol. 29, no. 2, pp. 1427-1434, 2002.

[23] C. Xu and A. A. Konnov, "Validation and analysis of detailed kinetic models for ethylene combustion," Energy, vol. 43, no. 1, pp. 19-29, 2012.

[24] J. Li, L. Yuan, and H. C. Mongia, "Simulation of combustion characteristics in a hydrogen fuelled lean single-element direct injection combustor," International Journal of Hydrogen Energy, vol. 42, no. 5, pp. 3536-3548, 2017.

[25] Z. Cai, X. Liu, C. Gong, M. Sun, Z. Wang, and X.-S. Bai, "Large Eddy Simulation of the fuel transport and mixing process in a scramjet combustor with rearwall-expansion cavity," Acta Astronautica, vol. 126, pp. 375-381, 2016.

[26] Z. Wang, Z. Cai, M. Sun, H. Wang, and Y. Zhang, "Large Eddy simulation of the flame stabilization process in a scramjet combustor with rearwall-expansion cavity," International Journal of Hydrogen Energy, vol. 41, no. 42, pp. 1927819288, 2016.

[27] A. Wanik and U. Schnell, "Some remarks on the PISO and SIMPLE algorithms for steady turbulent flow problems," Computers \& Fluids, vol. 17, no. 4, pp. 555-570, 1989. 
[28] M. Kuznetsov, V. Alekseev, Y. Yankin, and S. Dorofeev, "Slow and fast deflagrations in hydrocarbon-air mixtures," Combustion Science and Technology, vol. 174, no. 5-6, pp. 157-172, 2002.

[29] J. Li, P. Zhang, L. Yuan, Z. Pan, and Y. Zhu, "Flame propagation and detonation initiation distance of ethylene/oxygen in narrow gap," Applied Thermal Engineering, vol. 110, pp. 1274-1282, 2017. 


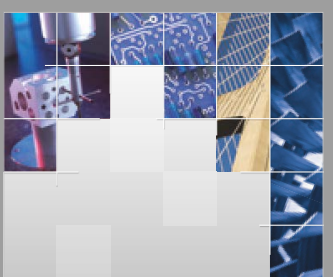

\section{Enfincering}
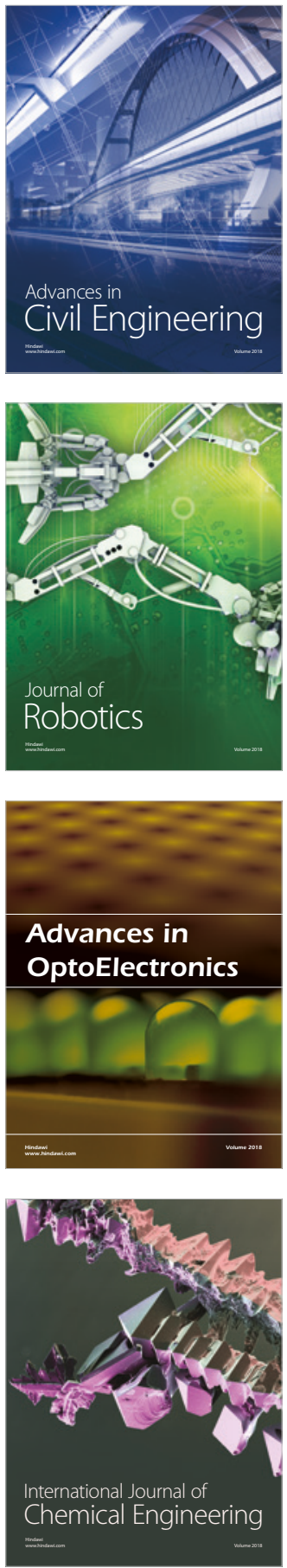

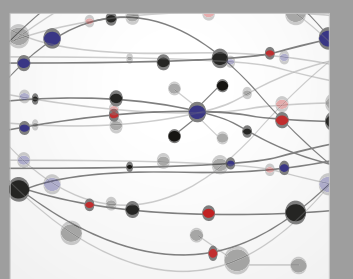

\section{Rotating \\ Machinery}

The Scientific World Journal

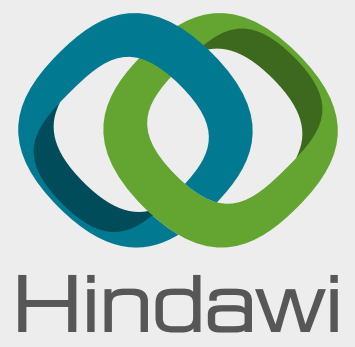

Submit your manuscripts at

www.hindawi.com
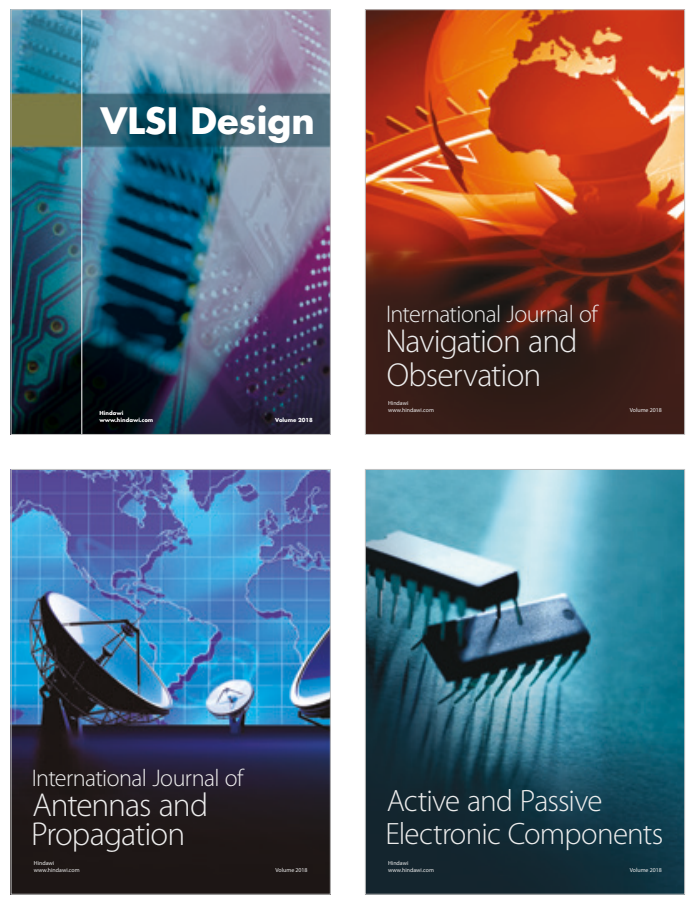
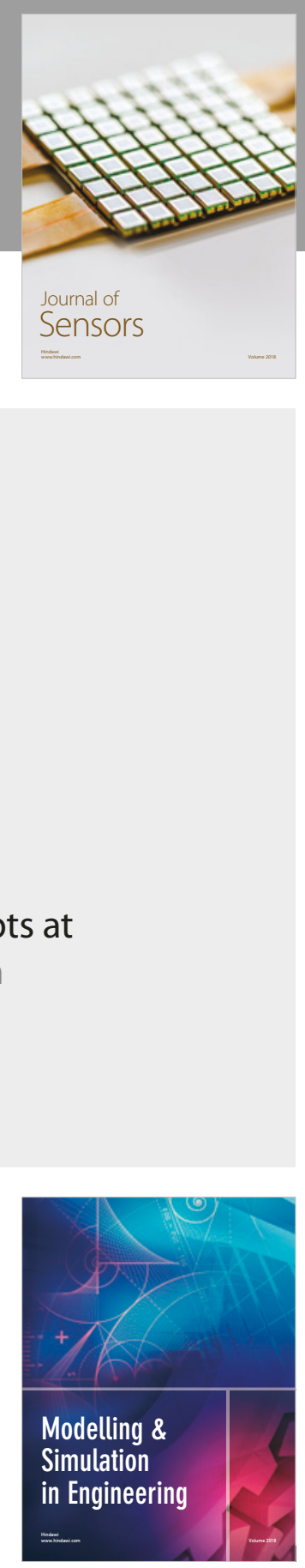

\section{Advances \\ Multimedia}
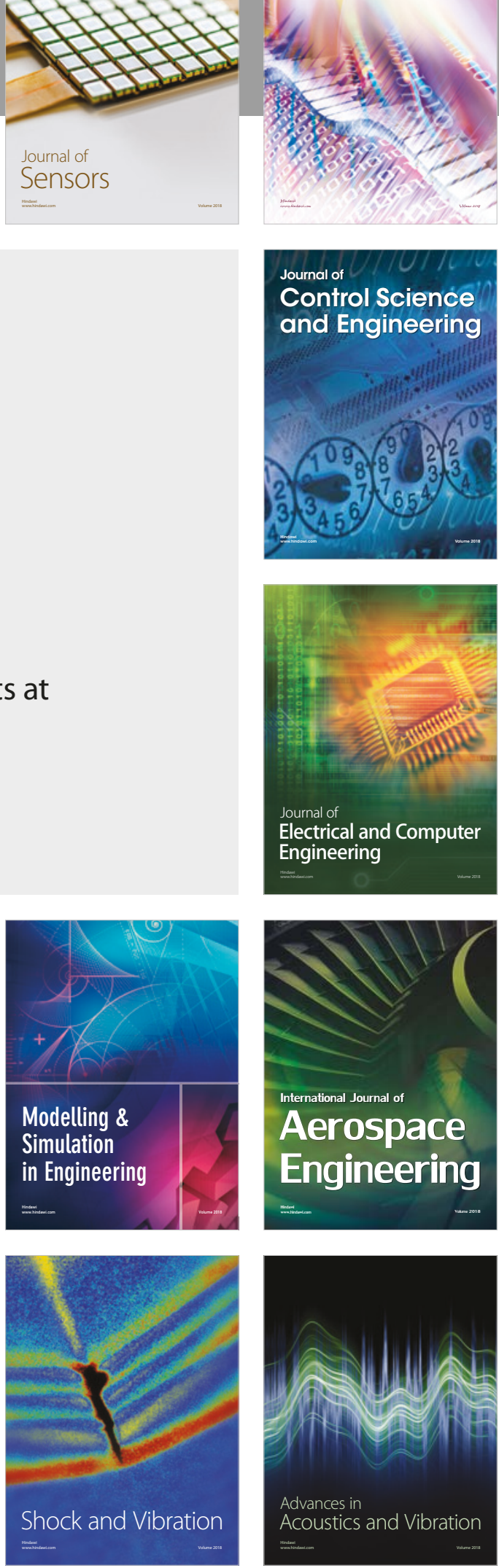